\title{
Fibroblastic niches prime T cell alloimmunity through Delta-like Notch ligands
}

\author{
Jooho Chung, ${ }^{1,2}$ Christen L. Ebens, ${ }^{2,3,4}$ Eric Perkey, ${ }^{1,2}$ Vedran Radojcic, ${ }^{2,5}$ Ute Koch, ${ }^{6}$ Leonardo Scarpellino, ${ }^{7}$ Alexander Tong, ${ }^{8}$ \\ Frederick Allen, ${ }^{8}$ Sherri Wood, ${ }^{9}$ Jiane Feng, ${ }^{9}$ Ann Friedman, ${ }^{2}$ David Granadier, ${ }^{2}$ Ivy T. Tran, ${ }^{2}$ Qian Chai, ${ }^{10}$ Lucas Onder, ${ }^{10}$ \\ Minhong Yan, ${ }^{11}$ Pavan Reddy, ${ }^{5}$ Bruce R. Blazar, ${ }^{4}$ Alex Y. Huang, ${ }^{8}$ Todd V. Brennan, ${ }^{12}$ D. Keith Bishop, ${ }^{9}$ Burkhard Ludewig, ${ }^{10}$ \\ Christian W. Siebel, ${ }^{11}$ Freddy Radtke, ${ }^{6}$ Sanjiv A. Luther, ${ }^{7}$ and Ivan Maillard ${ }^{2,5}$ \\ ${ }^{1}$ Graduate Program in Cellular and Molecular Biology, ${ }^{2}$ Life Sciences Institute, and ${ }^{3}$ Division of Hematology-Oncology, Department of Pediatrics, University of Michigan, Ann Arbor, Michigan, USA. \\ ${ }^{4}$ Division of Blood and Marrow Transplantation, Department of Pediatrics, University of Minnesota, Minneapolis, Minnesota, USA. ${ }^{5}$ Division of Hematology-Oncology, Department of Internal Medicine, \\ University of Michigan, Ann Arbor, Michigan, USA. Éćcole Polytechnique Fédérale de Lausanne (EPFL), Lausanne, Switzerland. Department of Biochemistry, University of Lausanne, Epalinges, Switzerland. \\ ${ }^{8}$ Medical Scientist Training Program and Division of Pediatric Hematology-Oncology, Department of Pediatrics, Case Western Reserve University, Cleveland, Ohio, USA. ${ }^{9}$ Department of Surgery, University \\ of Michigan, Ann Arbor, Michigan, USA. ${ }^{10}$ Institute of Immunobiology, Kantonsspital St. Gallen, St. Gallen, Switzerland. "Cenentech, South San Francisco, California, USA. ${ }^{12}$ Department of Surgery, \\ Duke University, Durham, North Carolina, USA.
}

\begin{abstract}
Alloimmune T cell responses induce graft-versus-host disease (CVHD), a serious complication of allogeneic bone marrow transplantation (allo-BMT). Although Notch signaling mediated by Delta-like 1/4 (DLL1/4) Notch ligands has emerged as a major regulator of CVHD pathogenesis, little is known about the timing of essential Notch signals and the cellular source of Notch ligands after allo-BMT. Here, we have shown that critical DLL1/4-mediated Notch signals are delivered to donor T cells during a short 48-hour window after transplantation in a mouse allo-BMT model. Stromal, but not hematopoietic, cells were the essential source of Notch ligands during in vivo priming of alloreactive T cells. CVHD could be prevented by selective inactivation of DII1 and DII4 in subsets of fibroblastic stromal cells that were derived from chemokine Cc/19expressing host cells, including fibroblastic reticular cells and follicular dendritic cells. However, neither T cell recruitment into secondary lymphoid organs nor initial T cell activation was affected by DII1/4 loss. Thus, we have uncovered a pathogenic function for fibroblastic stromal cells in alloimmune reactivity that can be dissociated from their homeostatic functions. Our results reveal what we believe to be a previously unrecognized Notch-mediated immunopathogenic role for stromal cell niches in secondary lymphoid organs after allo-BMT and define a framework of early cellular and molecular interactions that regulate $\mathrm{T}$ cell alloimmunity.
\end{abstract}

\section{Introduction}

Allogeneic bone marrow transplantation (allo-BMT) can cure hematological malignancies and other blood disorders. However, alloimmune $\mathrm{T}$ cell responses arising against foreign tissue antigens can trigger major complications such as graft-versus-host disease (GVHD) after allo-BMT (1-3). At the onset of GVHD, donor T cells are exposed to host tissue alloantigens in a highly inflammatory environment, inducing potent $\mathrm{T}$ cell immunoreactivity and subsequent pathogenicity. Current GVHD prophylactic and therapeutic strategies act through global immunosuppression and thus dimin-

\section{Related Commentary: p. 1215}

\section{Authorship note: J. Chung and C.L. Ebens contributed equally to this work} Note regarding evaluation of this manuscript: Manuscripts authored by scientists associated with Duke University, The University of North Carolina at Chapel Hill, Duke-NUS, and the Sanford-Burnham Medical Research Institute are handled not by members of the editorial board but rather by the science editors, who consult with selected external editors and reviewers.

Conflict of interest: M. Yan and C.W. Siebel are employed by Genentech.

Submitted: July 12, 2016; Accepted: January 5, 2017.

Reference information: / Clin Invest. 2017;127(4):1574-1588.

https://doi.org/10.1172/JCI89535. ish both beneficial and detrimental aspects of $\mathrm{T}$ cell alloreactivity. Efforts to develop new selective therapies to dampen GVHD have focused on early microenvironmental signals to donor alloreactive T cells (4). Many of these signals, which include alloantigens, costimulatory ligands, and local inflammatory mediators, have been assumed to derive from hematopoietic antigen-presenting cells (APCs) (5-7). However, recent work demonstrated that CD $4^{+}$ $\mathrm{T}$ cell-mediated alloresponses can occur in the absence of hematopoietic APCs as a source of alloantigens (8-10), suggesting that our current understanding of key early cellular and molecular events that drive donor T cell-mediated GVHD is incomplete.

The Notch pathway has emerged as a new, attractive therapeutic target to control the deleterious effects of T cell alloimmunity (11-17). Notch signaling is a conserved cell-to-cell communication pathway mediated by interactions between NOTCH1-4 receptors and their ligands Delta-like $1 / 3 / 4$ (DLL1/3/4) or JAGGED1/2 (JAG1/2) $(18,19)$. During GVHD, DLL1/4 ligands in the host engage NOTCH1/2 receptors in T cells, and transient systemic blockade of DLL1/4 Notch ligands with neutralizing antibodies results in long-term protection from GVHD (14). Despite the central role of Notch signaling in alloreactivity, the timing of critical Notch signals, the cellular source of Notch ligands, and the 
A

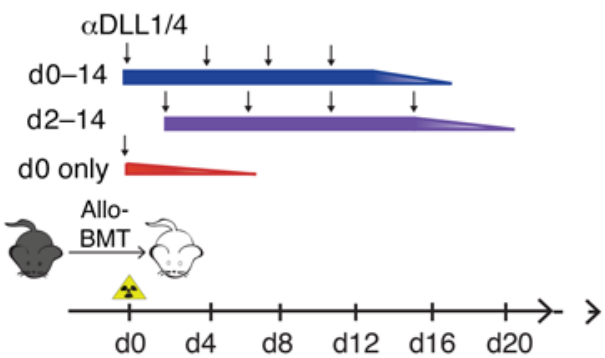

C

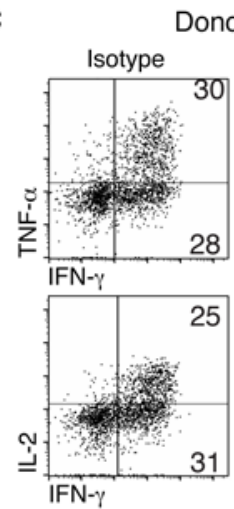

Donor $\mathrm{CD} 4^{+}$spleen day 6
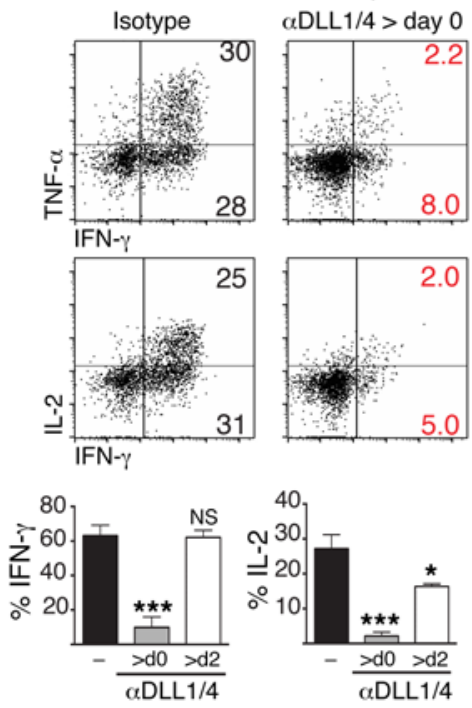
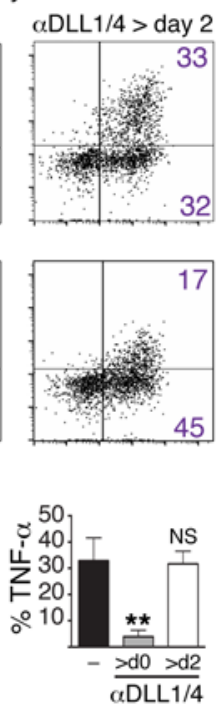

B
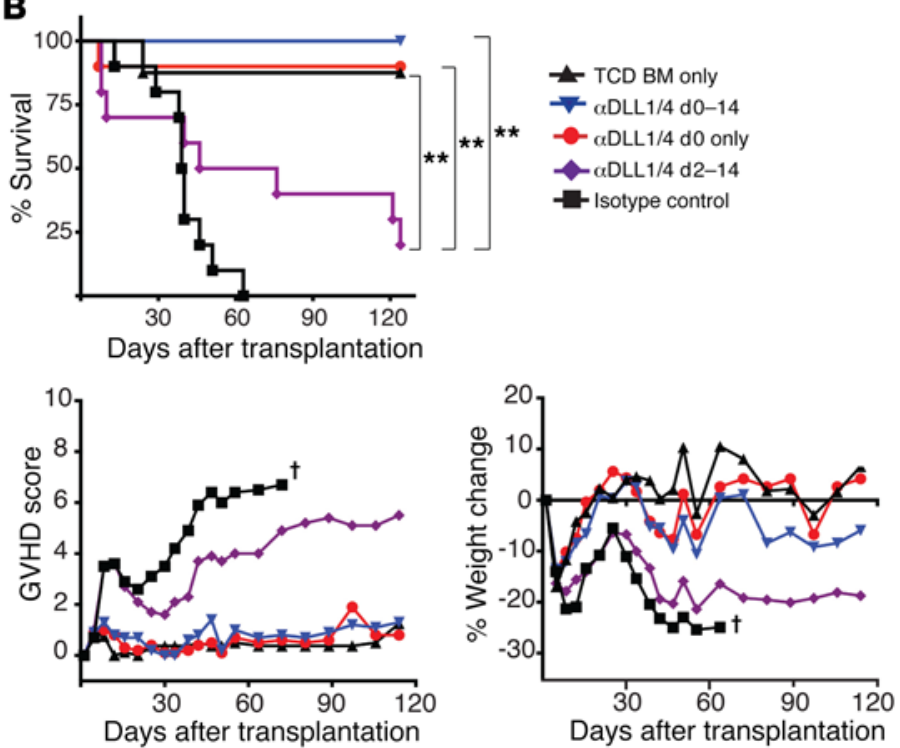

D
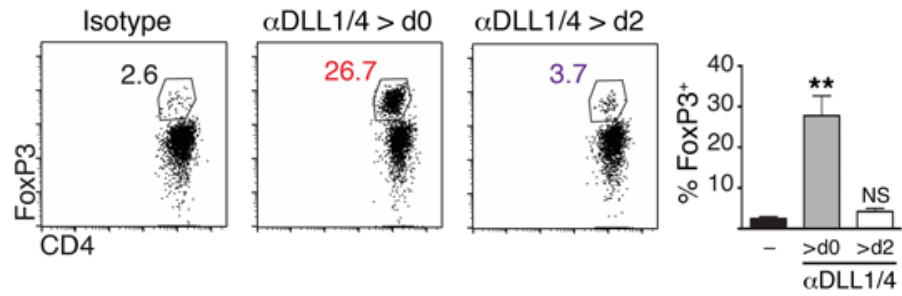

Figure 1. An early pulse of Notch signaling is critical to drive pathogenic T cell alloreactivity after BMT. (A) Dosing schedule of systemic neutralizing antibodies against DLL1 and DLL4 Notch ligands. (B) Survival, GVHD score, and weight of lethally irradiated (8.5 Gy) BALB/c mice transplanted with $5 \times 10^{6}$ T celldepleted (TCD) B6 BM or $5 \times 10^{6}$ TCD B6 BM plus $5 \times 10^{6}$ allogeneic B6 splenocytes. Isotype control versus anti-DLL1/4 antibodies were injected i.p., as shown in $\mathbf{A}$ ( $n=10$ mice/group). (C) Intracellular cytokine production by donor $C D 4^{+}$T cells after anti-CD3/CD28 restimulation on day 6 after transplantation ( $n=5$ mice/group). (D) Intracellular FoxP3 in donor CD4 ${ }^{+}$T cells on day 6 ( $n=5$ mice/group). ${ }^{*} P<0.05,{ }^{* *} P<0.01,{ }^{* *} P<0.001$, and NS $=P>0.05$, by unpaired, 2-tailed Student's $t$ test with Sidak's correction for multiple comparisons. Data are representative of at least 4 experiments; error bars indicate SD.

microanatomical context in which alloreactive $\mathrm{T}$ cells are exposed to Notch signaling in vivo remain unknown.

Early studies showed that hematopoietic APCs such as DCs can express DLL1 and DLL4 ligands in a TLR-inducible manner $(20,21)$. These observations led to the widely accepted concept that hematopoietic APCs can simultaneously deliver antigen and Notch ligands to modulate $\mathrm{T}$ cell function. In vitro studies supported this model, as TLR agonist-stimulated antigen-pulsed DCs induced naive $\mathrm{T}$ cells to differentiate in a Notch-regulated manner $(21,22)$. Similarly, a subpopulation of CD11c $\mathrm{c}^{+} \mathrm{DL} 4^{\mathrm{hi}} \mathrm{DCs}$ was capable of delivering Notch signals to alloreactive T cells in mixed lymphocyte reactions when purified from GVHD animal models (23). However, the in vivo relevance of APC-derived Notch signals has not been rigorously tested, and their importance has been inferred indirectly on the basis of their capacity to modulate $\mathrm{T}$ cell responses in vitro. Nonhematopoietic cells also express Notch ligands in multiple contexts, including in primary and secondary lymphoid organs (SLOs). In the thymus, FOXN1+ thymic epithelial cells act as nonredundant transducers of DLL4-mediated signals during $\mathrm{T}$ cell development (24-26). Blood and lymphatic endothelial cells (BECs and LECs) express high levels of DLL1 and DLL4 (27-31). Finally, genetic studies identified fibroblastic stromal cells in SLOs as nonredundant sources of DLL1-mediated Notch signals to marginal-zone B cells and DCs that express high levels of endothelial cell-specific adhesion molecule high $\left(\mathrm{ESAM}^{\mathrm{hi}} \mathrm{DCs}\right)$, as well as of DLL4-mediated signals to follicular helper T cells (32). Thus, multiple cellular sources have the potential to deliver Notch signals to $\mathrm{T}$ cells in vivo after allo-BMT, making it unclear whether critical signals are delivered in a defined microanatomical niche, and by hematopoietic or stromal cells.

To address these questions, we used a combination of systemic neutralizing antibodies and loss-of-function genetics to interrogate the in vivo spatial and temporal requirements for DLL1/4-mediated Notch signaling during GVHD. Surprisingly, we found that essential Notch signals were delivered to incoming $\mathrm{T}$ cells within 2 days of allo-BMT and that both donor and host hematopoietic cells were dispensable as a source of Notch ligands driving acute GVHD. In contrast, we found that subsets of nonhematopoietic fibroblastic stromal cells lineage traced with a Ccl19-Cre transgene functioned as the essential cellular source of Delta-like Notch ligands after allo-BMT. Interference with Notch ligands in fibroblastic stromal cells had selective effects on $\mathrm{T}$ cell alloreactivity and did not impair other functions of these cells in immune homeostasis. These findings change our understanding of the key early cellular and molec- 
A

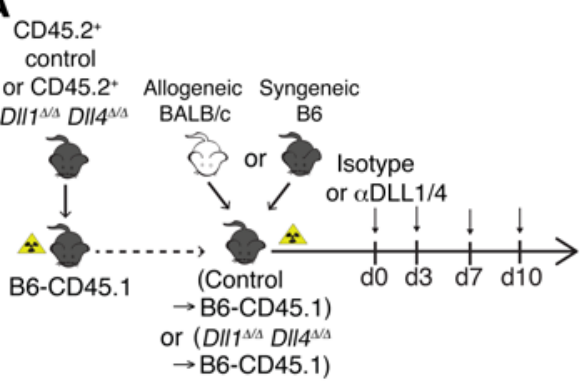

D

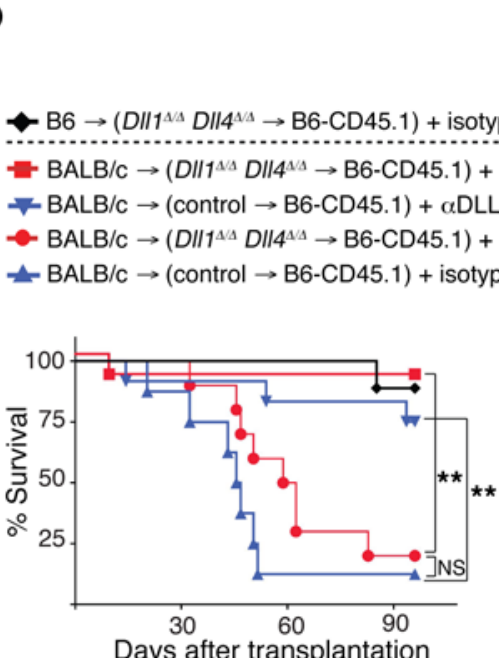

B

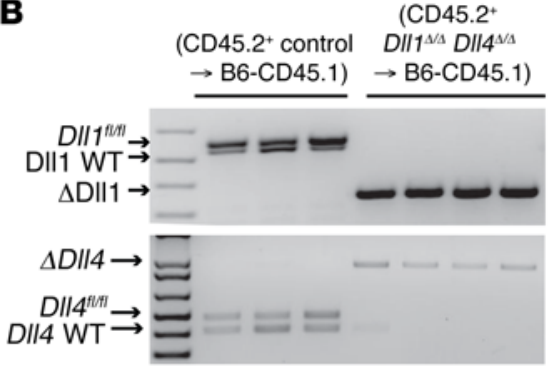

C

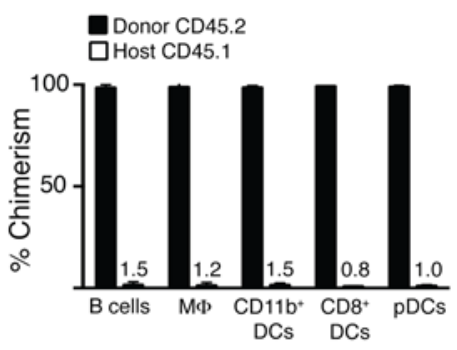

$\begin{array}{ccr}\text { Host } & \text { Host } & \\ \text { hematopoietic } & \text { nonhematopoietic } & \text { Systemic } \\ \text { DIl1/4 } & \text { DIl1/4 } & \alpha \text { DLL1/4 }\end{array}$
E

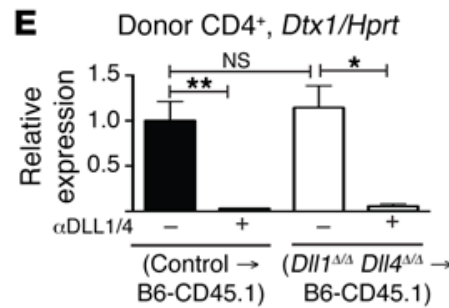

Donor CD8+, Dtx1/Hprt

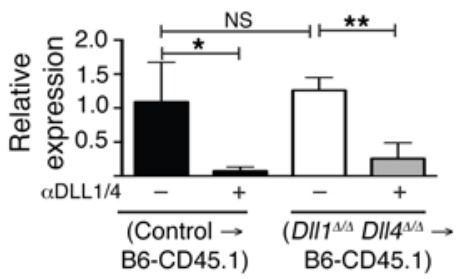

Figure 2. Host hematopoietic cells are dispensable as cellular sources of DLL1/4 Notch ligands in acute GVHD. (A) Experimental strategy. BM chime-

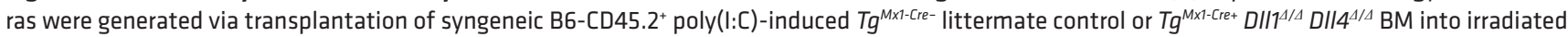
B6-CD45.1 recipients. After reestablishment of steady-state hematopoiesis 12 weeks later, BM chimeras were subjected to a second syngeneic or allogeneic transplant, with or without systemic anti-DLL1/4 blockade. (B) Quantification of DI/1 and DI/4 inactivation in sort-purified Gr1+CD11b+ blood myeloid cells from BM chimeras 12 weeks after transplantation (PCR). In this particular experiment, control BM chimeras were generated from poly(I:C)-induced $\operatorname{Tg}^{M \times 1-C r e-}$ DII $7^{f l+} D I / 4^{f l /+}$ donor mice. Each lane represents an individual mouse. (C) Donor chimerism (frequency of CD45.2+ donor cells) in the indicated splenic cell populations 12 weeks after transplantation. MФ, macrophages; pDCs, plasmacytoid DCs. (D) Survival and weight loss of lethally irradiated (11 Gy) BM chimeras transplanted with $8 \times 10^{6}$ TCD BM plus $30 \times 10^{6}$ B6 splenocytes (syngeneic control) or $30 \times 10^{6}$ allogeneic BALB/c splenocytes (allo-BMT). Isotype control or anti-DLL1/4 antibodies were injected i.p. on days $0,3,7$, and 10 ( $n=10$ mice/group). (E) Abundance of Dtx1 Notch target gene transcripts (qRTPCR) in sort-purified donor CD4+ T cells and CD8 ${ }^{+}$cells on day 6 ( $n=5$ mice/group). ${ }^{*} P<0.05,{ }^{*} P<0.01$, and NS $=P>0.05$, by unpaired, 2 -tailed Student's $t$ test with Sidak's correction for multiple comparisons. Data are representative of at least 2 experiments; error bars indicate SD.

ular events that condition the outcome of T cell alloimmunity. In addition, they pave the way toward the development of targeted therapeutic approaches to block Notch signaling and other stromal niche-derived pathogenic signals in GVHD and other T cellmediated immune disorders.

\section{Results}

Early DLL1/4-mediated Notch signals drive $T$ cell alloreactivity during acute GVHD. To understand the temporal requirement for Notch signaling after allo-BMT, we used neutralizing antibodies against DLL1 and DLL4 Notch ligands in an irradiation-dependent MHC-mismatched mouse allo-BMT model (Figure 1A). A single injection of DLL1- and DLL4-neutralizing antibodies before alloBMT was sufficient for long-term protection from GVHD lethality and morbidity, decreased production of $\mathrm{T}$ cell proinflammatory cytokines by $\mathrm{CD}^{+}$and $\mathrm{CD}^{+} \mathrm{T}$ cells, and expanded FoxP3 ${ }^{+}$Tregs (Figure 1, B-D, Supplemental Figure 1A; supplemental material available online with this article; https://doi.org/10.1172/
JCI89535DS1). In contrast, delayed initiation of antibody treatment by only 2 days resulted in loss of clinical protection, persistent IFN- $\gamma$ and TNF- $\alpha$ production, and no increase in Treg numbers. DLL1/4 blockade inhibited cytokine production and Notch target gene expression in $\mathrm{T}$ cells recovered from both spleens and lymph nodes (LNs) (Supplemental Figure 1, B and C). Notch target gene expression was decreased in proliferating donor-derived alloreactive $\mathrm{T}$ cells isolated during the temporal window of Notch sensitivity (Supplemental Figure 1, D and E). These data identify an early pulse of Notch signaling delivered within 2 days of alloBMT that programs T cells to a pathogenic state of reactivity.

Donor and host hematopoietic cells are dispensable sources of Notch ligands during GVHD. The early window of sensitivity to Notch inhibition suggested that $\mathrm{T}$ cells might receive Notch signals from residual host hematopoietic APCs, which can express both alloantigens and Notch ligands (21-23, 33-35). To test whether hematopoietic APCs were responsible for delivering Notch signals to donor alloreactive $\mathrm{T}$ cells, we generated BM chimeras lacking DLL1/4 
A
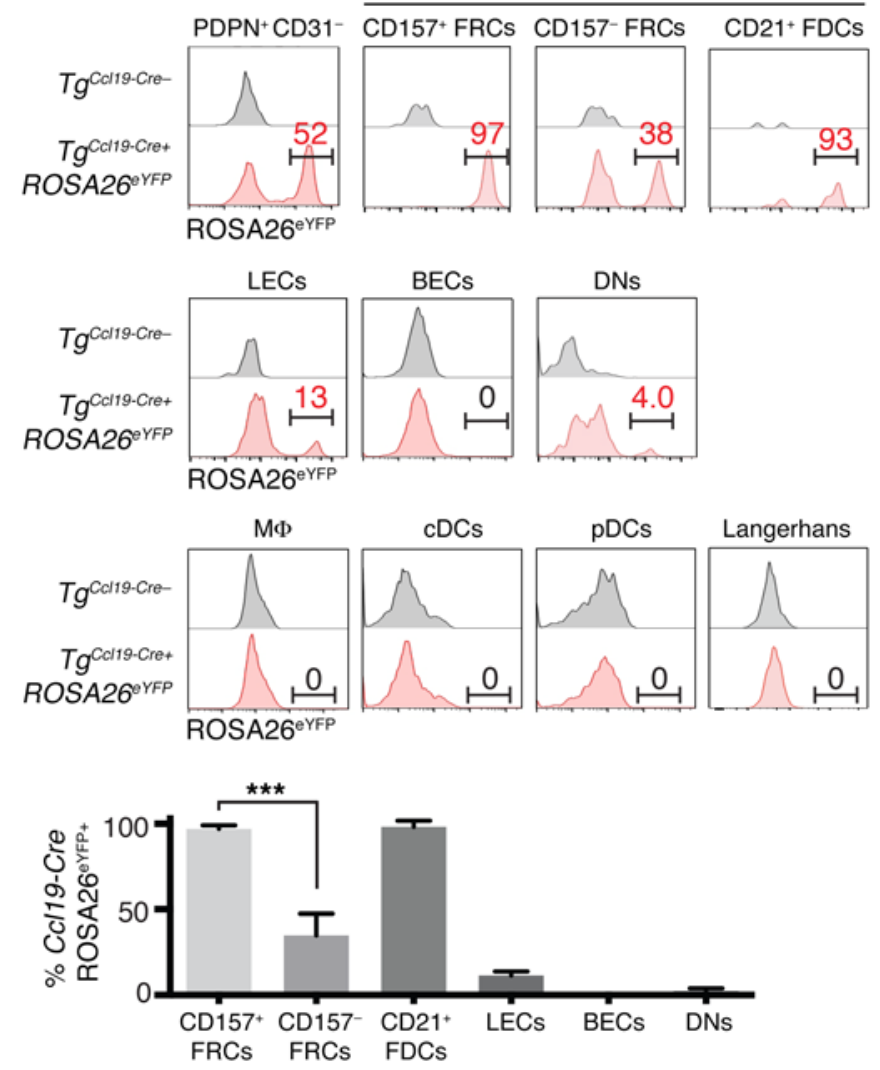

B

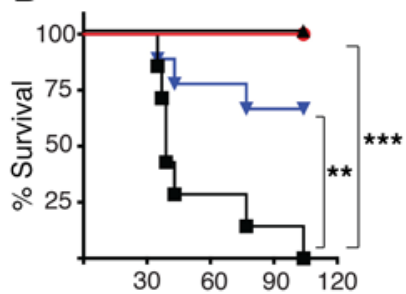

Days after transplantation

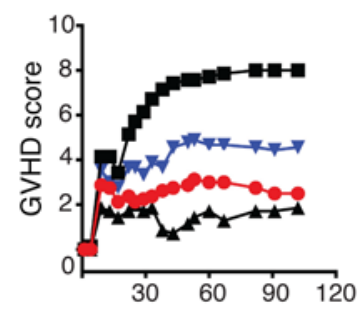

Days after transplantation

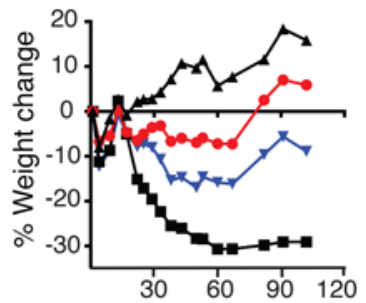

Days after transplantation
C
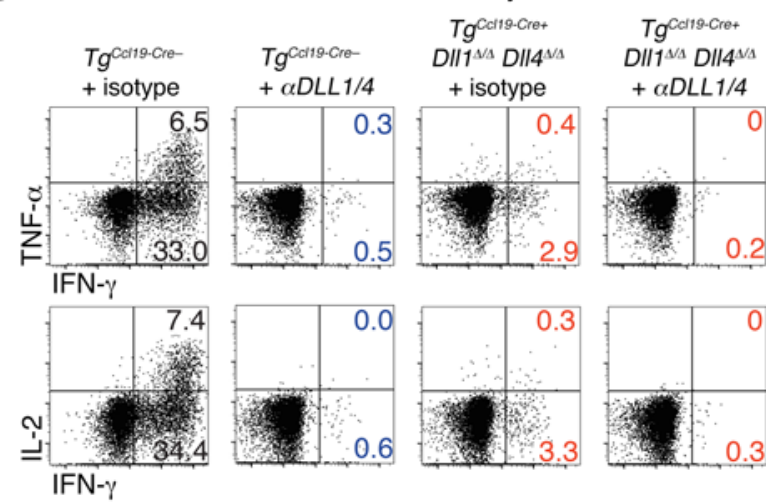

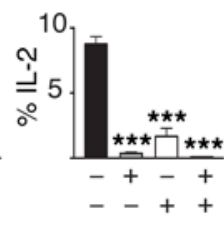

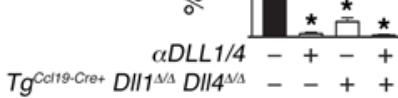

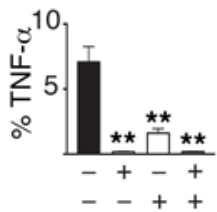

D

CFSE $^{\text {diluted }}$ donor $\mathrm{CD}^{+} \mathrm{T}$ cells day 2
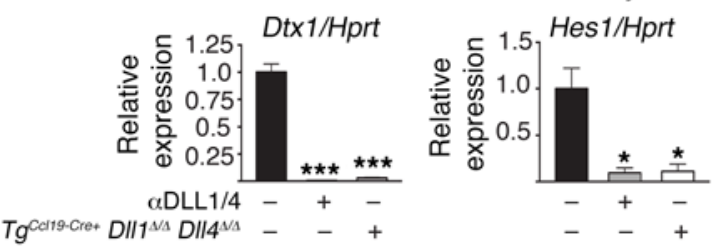

Figure 3. Ccl19-Cre ${ }^{+}$lineage-traced stromal cells are the critical cellular source of DLL1/4 Notch ligands during acute GVHD. (A) LNs were collected on day 1.5 after transplantation from lethally irradiated $T g^{\text {Ccllg-Cret }} R O S A 26^{\text {eYFP }}$ mice receiving allogeneic BALB/C splenocytes and enzymatically digested. (A, top) eYFP expression in LN-resident bulk fibroblastic stromal cells (PDPN+CD31-) as well as subfractionated CD157+ ${ }^{+}$FRCs, CD157 FRCs, and CD21+ FDCs. (A, middle) eYFP in LECs, BECs, PDPN-CD31- stromal cells (DNs). (A, bottom) eYFP in macrophages, conventional DCs (CDCs), pDCs, and skin-derived Langerhans cells. Bars in histograms define gating for $\mathrm{eYFP}^{+}$cells, and numbers indicate the percentage of gated eYFP+ cells within parental cell populations, as identified by flow cytometric analysis. Bar graph in $\mathbf{A}$ shows the mean percentage of eYFP expression in each indicated nonhematopoietic subset ( $n=4$ mice/group; error bars indicate SD). (B) Survival, GVHD score, and weight of lethally irradiated (12 Gy) littermate control

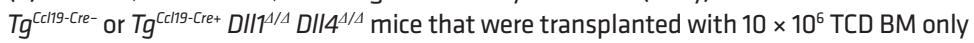
or $10 \times 10^{6} \mathrm{TCD}$ BM plus $20 \times 10^{6}$ allogeneic BALB/c splenocytes. Isotype control or antiDLL1/4-neutralizing antibodies were injected i.p. on days $0,3,7$, and 10 ( $n=10$ mice/ group). (C) Intracellular cytokines in donor $\mathrm{CD}^{+}$cells after anti-CD3/CD28 restimulation on day 6 ( $n=5$ mice/group). (D) Relative abundance of Dtx1 and Hes1 Notch target gene transcripts in donor $\mathrm{CD}^{+} \mathrm{T}$ cells sort purified from $\mathrm{Tg}^{\text {cccl19-cre- }}$ plus isotype control, $\mathrm{Tg}^{\text {cchl9-cre- }}$ plus anti-DLL1/4, or $\mathrm{Tg}^{\text {Ccllg-Cre+ }} \mathrm{DI/17^{1/4 }} \mathrm{DIl4^{4/4 }}$ recipient mice on day 2 after transplantation ( $n=5$ mice/group). ${ }^{*} P<0.05,{ }^{* *} P<0.01$, and ${ }^{* * *} P<0.001$, by unpaired, 2 -tailed Student's $t$ test with Sidak's correction for multiple comparisons. Data are representative of at least 5 experiments; error bars indicate SD. only in hematopoietic cells with poly(I:C)-induced $\mathrm{Tg}^{\mathrm{M} x 1-\mathrm{Cre+}} \mathrm{Dll1} 1^{1 / 4}$ Dll4 ${ }^{\Delta / \Delta}$ BM (designated as Dll1 ${ }^{\Delta / \Delta}$ Dll4 ${ }^{\Delta / \Delta} \rightarrow$ B6-CD45.1) (Figure 2A). This strategy led to efficient Cre-mediated recombination and high donor chimerism in all hematopoietic APCs (Figure 2, B and C). Allo-BMT into Dll1 $1^{1 / 4} \mathrm{Dll} 4^{4 / \Delta} \rightarrow \mathrm{B} 6-\mathrm{CD} 45.1$ chimeras as compared with control BM chimeras did not protect mice from GVHD mortality or morbidity (Figure 2D). In contrast, systemic antibody-mediated DLL1/DLL4 blockade protected both Dll1 $1^{\Delta / \Delta}$ Dll4 $4^{4 / \Delta} \rightarrow$ B6CD45.1 and control BM chimeras from GVHD lethality. Consistent with persistent exposure to DLL1/4 ligands in these mice, donor- derived T cells expressed equivalent amounts of Notch target gene transcripts in Dll1 ${ }^{1 / \Delta}$ Dll4 $4^{4 / 4} \rightarrow$ B6-CD45.1 and control chimeras, but transcript abundance remained sensitive to systemic anti-DLL1/4 antibodies (Figure 2E). Thus, host hematopoietic cells were dispensable as a source of Notch ligands after allo-BMT.

To rule out redundant DLL1/4 expression in donor and host hematopoietic cells, we backcrossed $T g^{M x 1-C r e+} D l l 1^{f / f l} D l l 4^{f / f l}$ mice onto the $\mathrm{BALB} / \mathrm{c}$ background and generated $\mathrm{BM}$ chimeras with poly(I:C)-induced $T g^{M x 1^{-C r e+}} D l l 1^{1 / \Delta}$ Dll4 ${ }^{4 / \Delta}$ donors (Dll1 $1^{1 / 4} D l l 4^{4 / \Delta} \rightarrow$ BALB/c) (Supplemental Figure 2A). Transplantation of Dll1 $1^{1 / 4}$ 

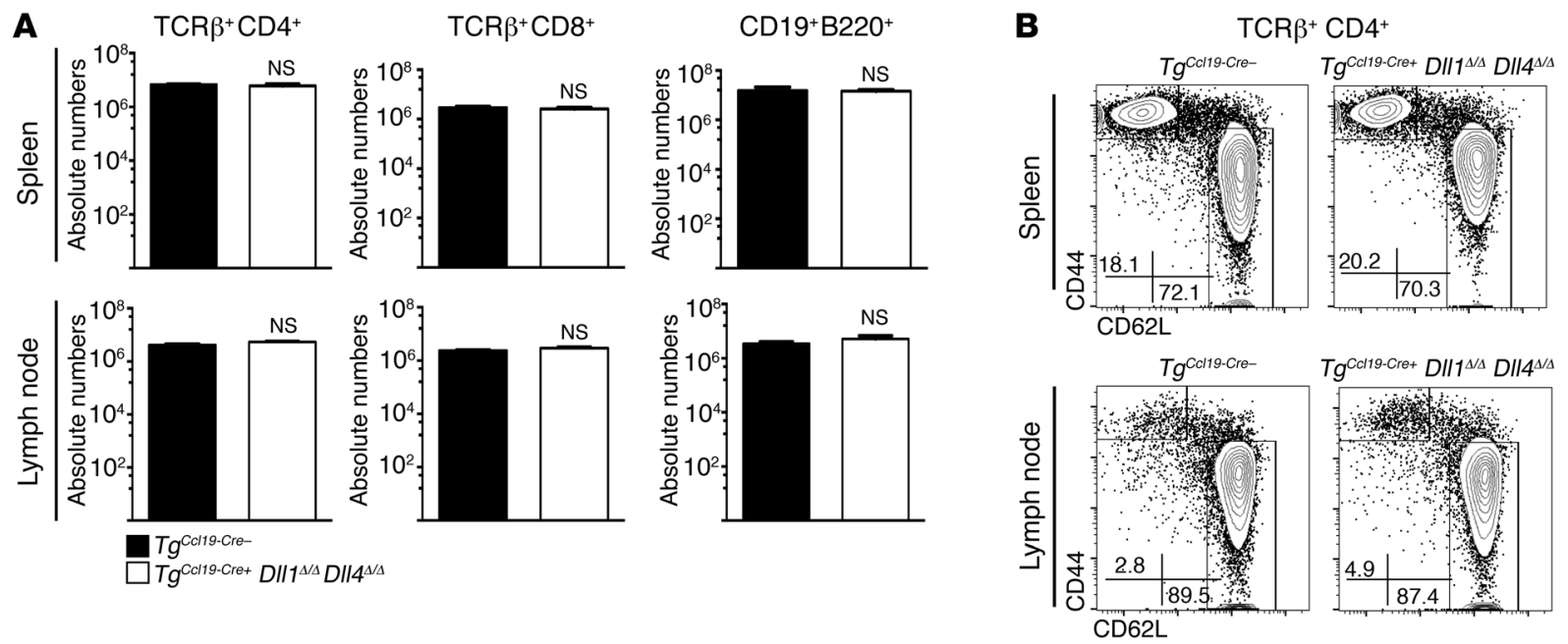

C

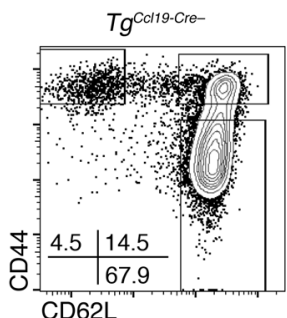

$\mathrm{TCR} \beta^{+} \mathrm{CD} 8^{+}$spleen

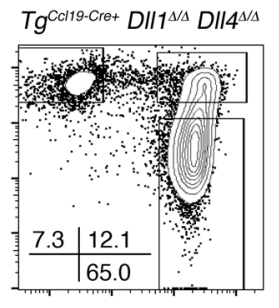

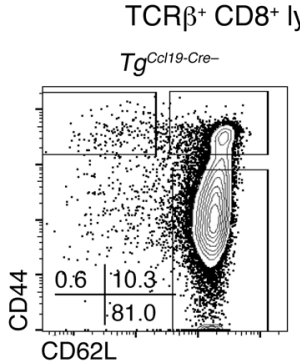

TCR $\beta^{+}$CD8 ${ }^{+}$lymph node

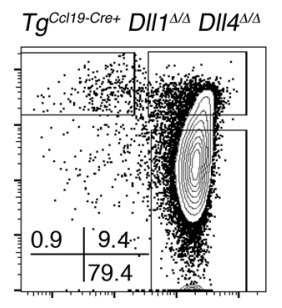

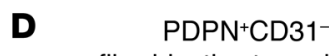

fibroblastic stromal cells

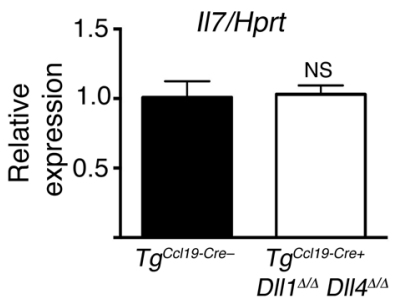

Figure 4. Cc/19-Cre-mediated DII1 and DII4 inactivation preserves lymphocyte numbers and distribution in SLOs at steady state. (A) Absolute numbers

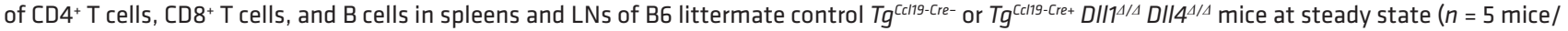

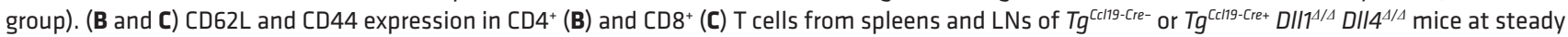

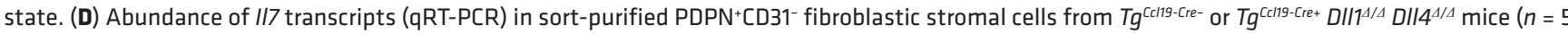
mice/group). NS $=P>0.05$, by unpaired, 2-tailed Student's $t$ test. Data are representative of at least 3 experiments; error bars indicate SD.

Dll4 $4^{4 / 4} \rightarrow$ B6-CD 45.1 donor cells into Dll1 ${ }^{4 / 4} \mathrm{Dll} 4^{4 / 4} \rightarrow \mathrm{BALB} / \mathrm{c}$ recipients (designated as $D l l 1^{1 / 4} \mathrm{D} l 4^{4 / 4} \rightarrow D l l 1^{1 / 4} \mathrm{D} l l 4^{\Delta / 4}$ ) had no impact on $\mathrm{T}$ cell cytokine production or Treg frequencies (Supplemental Figure 2, B-D), despite sensitivity to systemic DLL1/DLL4 blockade. Donor-derived T cells from $\mathrm{Dll1} 1^{1 / \Delta} \mathrm{Dll} 4^{4 / \Delta} \rightarrow \mathrm{Dll}^{1 / \Delta} \mathrm{Dll} 4^{4 / \Delta}$ recipient mice retained abundant Notch target gene transcripts (Supplemental Figure 2E). Therefore, both donor and host hematopoietic cells were dispensable sources of DLL1/4 Notch ligands during GVHD.

Ccl19-Cre ${ }^{+}$stromal cells are critical sources of Notch ligands during GVHD. Among multiple radioresistant nonhematopoietic cells that express Notch ligands in SLOs, fibroblastic stromal cells lineage traced with Ccl19-Cre act as a non-motile source of Notch ligands to immune cells in steady-state conditions (32). To assess the importance of these cells during allo-BMT, we conditionally inactivated Dll1 and Dll4 with Ccl19-Cre (hereafter referred to as $\mathrm{Tg}^{\mathrm{Ccl19-Cre+}} \mathrm{Dll1} 1^{1 / 4}$ $D l l 4^{4 / 4}$ ) (36-38). After irradiation and allo-BMT, lineage tracing by Ccl19-Cre was detected in $\mathrm{PDPN}^{+} \mathrm{CD} 31^{-}$fibroblastic stromal cells, as assessed by Cre-inducible enhanced yellow fluorescent protein (eYFP) expression from a ROSA26 $6^{\text {eYF }}$ allele (Figure 3A and Supplemental Figure 3A). Further characterization of Ccl19-Cre activity within cellular subsets of $\mathrm{PDPN}^{+} \mathrm{CD} 31^{-}$stromal cells showed eYFP in more than $95 \%$ of cells from the $\mathrm{CD} 157^{\mathrm{hi}} \mathrm{CD} 21^{-}$subset (consistent with fibroblastic reticular cells [FRCs]) and from the $\mathrm{CD} 157^{\mathrm{hi}} \mathrm{CD} 21^{+}$ subset (consistent with follicular dendritic cells [FDCs]). Tg ${ }^{\text {Ccll9-Cre }}$ also lineage traced a smaller fraction of $\mathrm{PDPN}^{+} \mathrm{CD} 31^{+} \mathrm{LECs}$ and very few $\mathrm{PDPN}^{-} \mathrm{CD} 31^{-}$stromal cells. In contrast, $\mathrm{Tg}^{\text {Ccll9-Cre }}$ was inactive in $\mathrm{PDPN}^{-} \mathrm{CD} 31^{+}$BECs and in all hematopoietic cells, including professional APCs in SLOs and Langerhans cells isolated from the epidermis (Figure 3A and Supplemental Figure 3, A-D). Thus, $\mathrm{Tg}$ Ccl19-Cre had a pattern of activity suitable for inactivation of Dll1/4 selectively in subsets of fibroblastic stromal cells (including FRCs and FDCs) and in a small fraction of LECs.

$\mathrm{Tg}^{\text {Ccl19-Cre+ }} \mathrm{Dll1}^{1 / \Delta} \mathrm{Dll} 4^{\Delta / \Delta}$ mice were highly protected from GVHD lethality and morbidity (Figure 3B). Markedly fewer donor $\mathrm{T}$ cells from $\mathrm{Tg}^{\mathrm{Ccl19-Cre+}} \mathrm{Dll}^{1 / 4} \mathrm{Dll} 4^{4 / \Delta}$ recipients produced proinflammatory cytokines, as observed with systemic DLL1/4 blockade (Figure 3C and Supplemental Figure 4). Notch target gene transcripts were profoundly decreased in donor-derived T cells isolated from $\mathrm{Tg}^{\text {Ccll9-Cret }} \mathrm{Dll1}^{1 / 4} \mathrm{Dll4}^{4 / 4}$ recipients (Figure 3D). As shown with anti-DLL1/4 antibodies (Supplemental Figure 1, B and C), the effects of Ccl19-Cre-mediated Dll1/4 loss were observed in the spleen (which lacks LECs) as well as in LNs (Figure 3, C and D, and data not shown). Thus, nonhematopoietic cells lineage traced by Ccl19-Cre were the dominant source of DLL1/DLL4 Notch ligands encountered in vivo by donor T cells after allo-BMT.

$\mathrm{T}$ cell cytokine production was preserved after allo-BMT into $\mathrm{Tg}^{\mathrm{Ccl19-Cre+}} \mathrm{Dll1}^{+/+} \mathrm{Dll4} 4^{+/+}$control recipients, ruling out Cre toxicity (Supplemental Figure 5). To assess whether DLL1/4 blockade 
A $\mathrm{TCR}^{+}{ }^{+\mathrm{CD}} 4^{+}$day 2.5

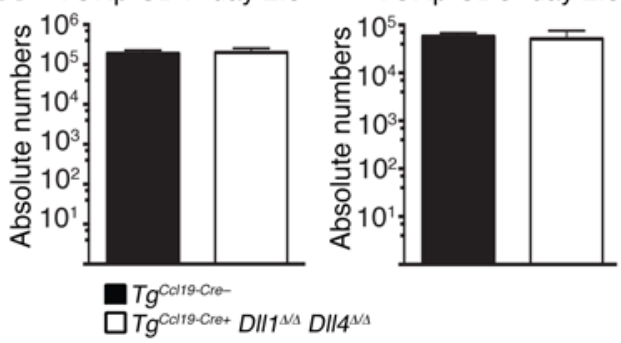

B

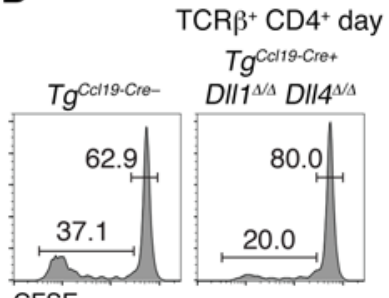

CFSE

TCR $\beta^{+}$CD $8+$ day 2.5

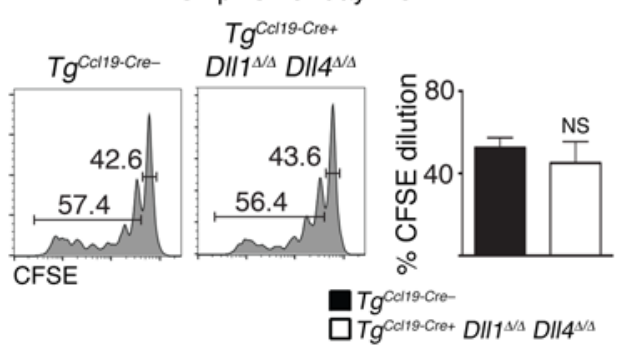

C Donor $\mathrm{CD}^{+} \mathrm{T}$ cells day 6

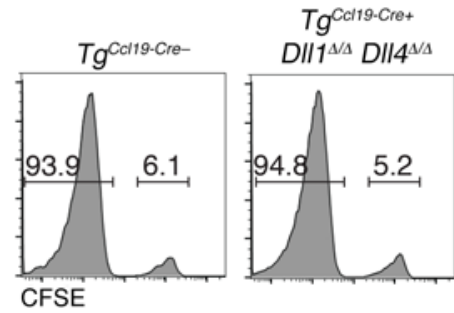

D $\mathrm{TCR}^{+}{ }^{+} \mathrm{CD} 4+{ }^{+} \mathrm{CFSE}{ }^{\text {diluted }}$ day 2.5 - Isotype - Tg $g^{\text {colig-Cre- }}$

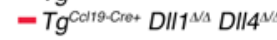

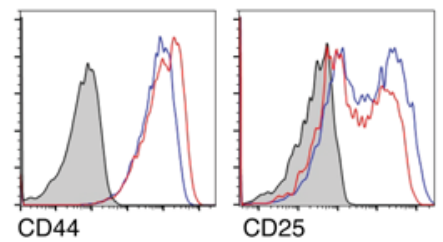

E $\mathrm{TCR}^{+} \mathrm{CD}^{+} \mathrm{CFSE}^{\text {diluted }}$ day 2.5 - Isotype
- Tg

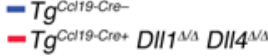

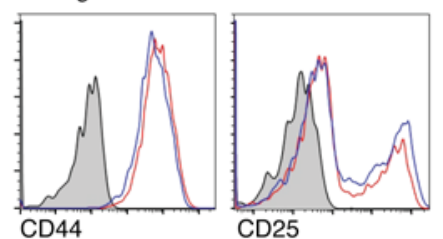

Donor CD8+ $\mathrm{T}$ cells day 6

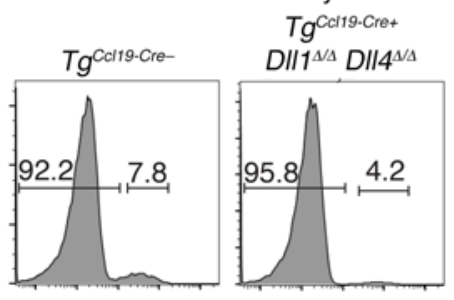

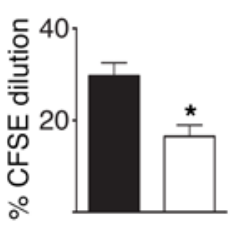

CD44

$\mathrm{TCR} \beta^{+} \mathrm{CD} 4{ }^{+} \mathrm{CFSE}^{\text {dilued }}$ day 2

$\mathbf{F}$

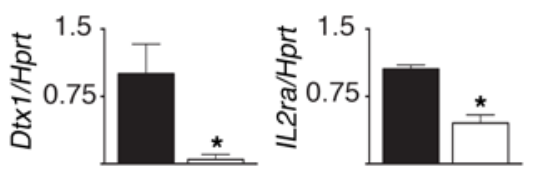

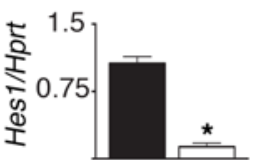
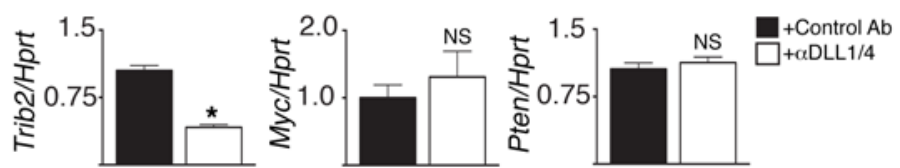

Figure 5. Cc119-Cre-mediated DII1 and DII4 inactivation does not impair T cell recruitment or proliferation in SLOs after irradiation, but selectively affects Notch target gene transcripts. (A-E) Absolute numbers (A), proliferation (CFSE dilution) on day 2.5 (B) versus day 6 after transplantation (C), and expression of activation markers. Bars in histograms define gating for proliferated CFSE ${ }^{\text {low }}$ and unproliferated CFSE ${ }^{\text {hi }}$ cells, and numbers indicate the percentage of gated cells among parental cell populations, as identified by flow cytometric analysis. Bar graphs represent the mean percentage of proliferated (CFSE ${ }^{\text {low }}$ ) cells in each population ( $n=5$ mice/group); error bars indicate SD. ( $\mathbf{D}$ and $\mathbf{E}$ ) by donor-derived CD4 ${ }^{+}$and CD8 ${ }^{+} T$ cells after transplantation into lethally irradiated (12 Gy) littermate control $\mathrm{Tg}^{\text {Cccl19-Cre- }}$ or $\mathrm{Tg}^{\text {ccl19-Cre+ }}$ DI/1/1/4 DII4 ${ }^{1 / 4} \mathrm{~B} 6$ recipient mice. Donor cells were isolated on day 2.5 or day 6 after transplantation ( $n=5$ mice/group). (F) Abundance of the indicated transcripts (qRT-PCR) in sort-purified donor-derived CFSE diluted BALB/c CD4 ${ }^{+}$T cells on day 2 after transplantation into irradiated B6 hosts treated with or without anti-DLL1/4 antibodies. ${ }^{*} P<0.05,{ }^{* *} P<0.01, \mathrm{NS}=P>0.05$, by unpaired, 2-tailed Student's $t$ test. Data are representative of at least 3 experiments; error bars indicate SD. MFI, mean fluorescence intensity.

might impact GVHD through effects that are independent of $\mathrm{T}$ cells, we established an experimental system that preserved stroma-derived Notch signals in $\mathrm{T}$ cells, but removed Notchdependent non-T cells. Past work showed that NOTCH2 receptors engaged by stromal DLL1/4 ligands control the development and/ or maintenance of $\mathrm{ESAM}^{\mathrm{hi}}$ DCs, $\mathrm{CD} 8^{+} \mathrm{DCs}$, and marginal-zone B cells in the spleen (39-41). We generated syngeneic BM chimeras using poly(I:C)-induced $T g^{\text {Mxl-Cret }} N$ otch $2^{4 / 4}$ or control $T g^{M x l-C r e-}$ Notch $2^{A / f l}$ progenitors (Supplemental Figure 6A). These BM chimeras lacked marginal-zone B cells and had decreased numbers of NOTCH2-dependent $\mathrm{CD}^{+}$and ESAM ${ }^{\text {hi }}$ DCs, as expected (Supplemental Figure 6B and refs. 39-41). We subjected these
BM chimeras to allogeneic BMT with MHC-mismatched BALB/c $\mathrm{BM}$ and purified $\mathrm{T}$ cells. With this approach, recipient mice lacked NOTCH2-dependent host populations but had preserved stromal DLL1/4 expression (Supplemental Figure 6, A, C, and D). Systemic DLL1/4 inhibition blocked the production of IL-2, IFN- $\gamma$, and TNF- $\alpha$ by donor-derived T cells after allo-BMT. In contrast,

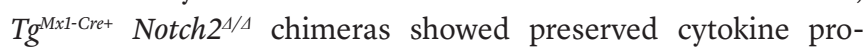
duction in LNs and increased, but not decreased, production in donor-derived splenic $\mathrm{T}$ cells. These findings indicate that loss of NOTCH2-dependent host splenic cells cannot indirectly explain the impact of DLL1/4 inhibition during GVHD, which is consistent with the observed direct effects of DLL1/4 on donor T cells. 


\author{
A
}

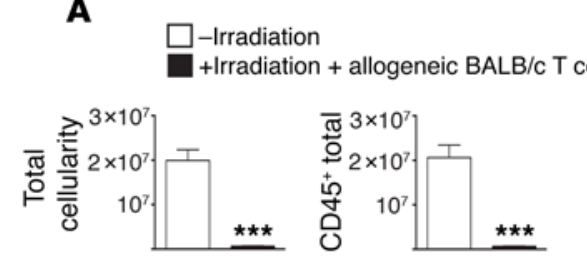

B
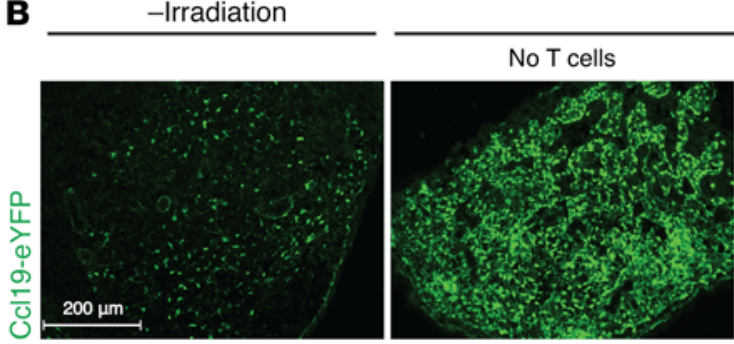

Lymph node $T g^{\text {Ccl19-Cret }}$ ROSA26 $6^{\text {erF }}$

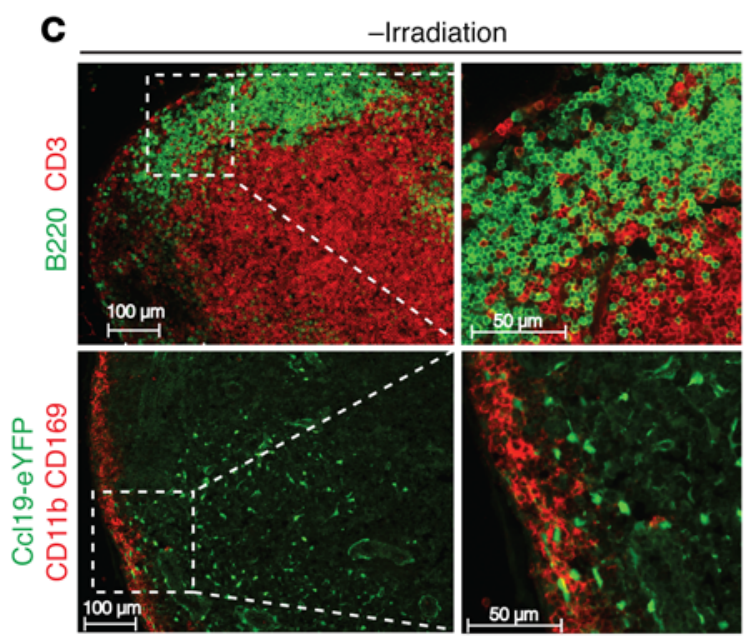

D

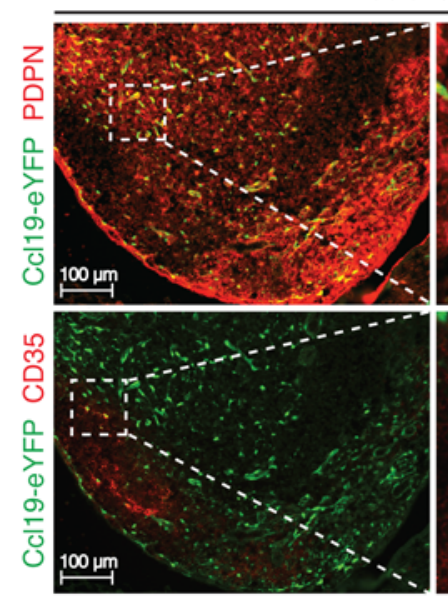

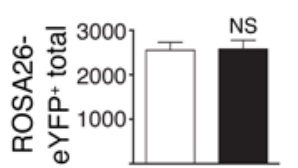
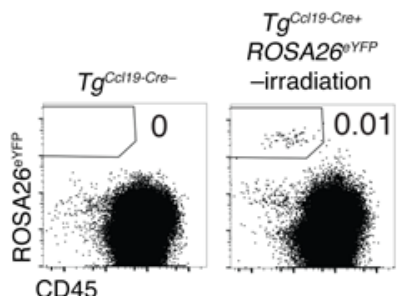

TgCal19-Cre+

ROSA26 $6^{\text {YFP }}$ +irradiation

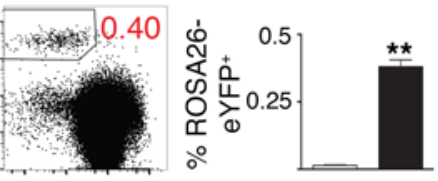

+Irradiation

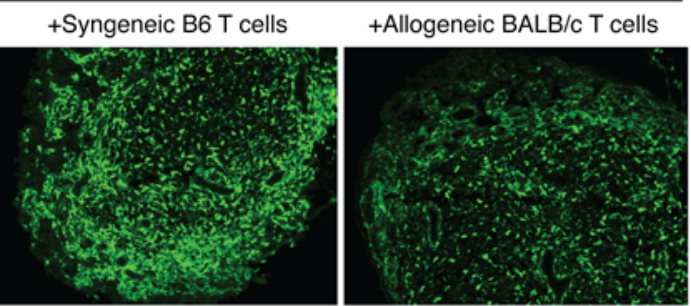

+Allogeneic BALB/c T cells
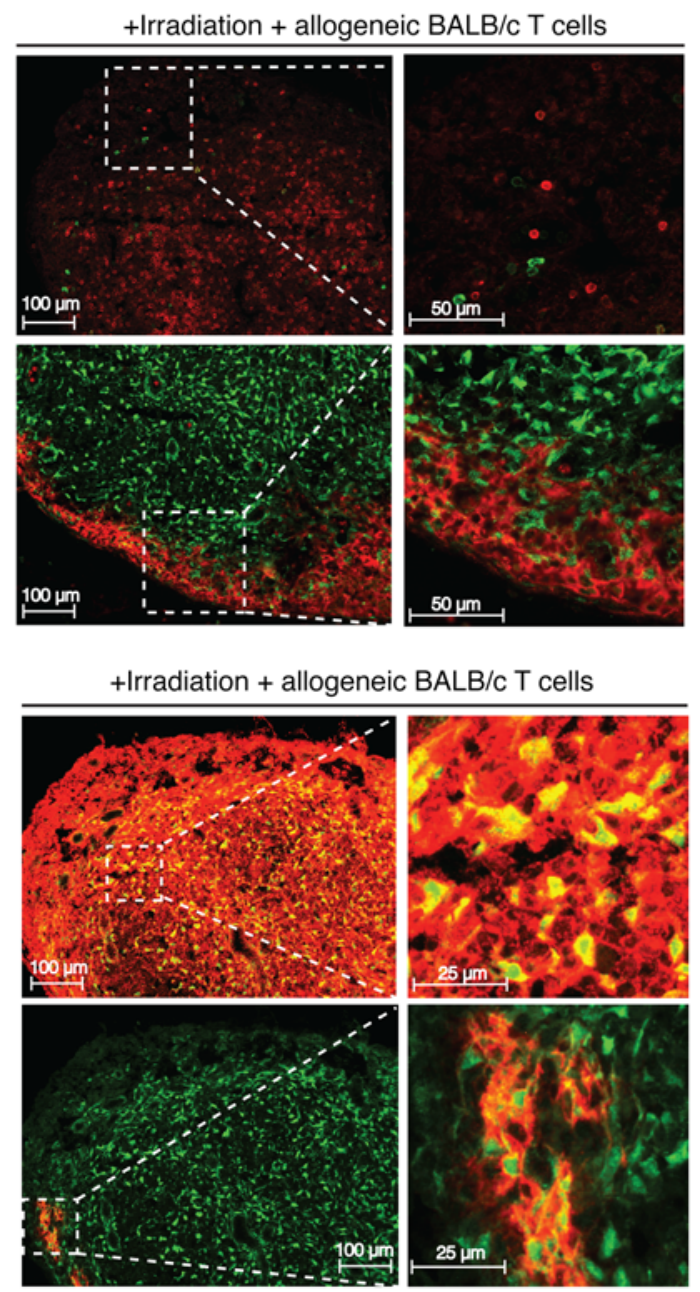

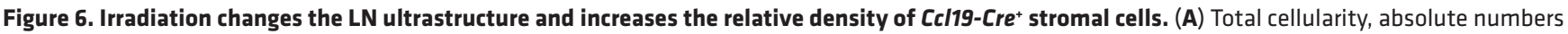

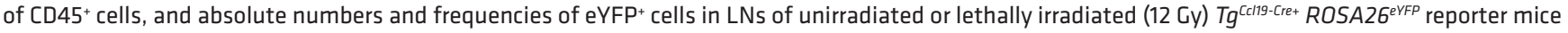
receiving allogeneic BALB/c splenocytes ( $n=6$ mice/group). ${ }^{* *} P<0.01,{ }^{* *} P<0.001$, NS $=P>0.05$, by unpaired, 2-tailed Student's $t$ test. (B) Immunofluorescence microscopy images of LN cryosections from $\mathrm{Tg}^{\text {Cchlg-Cre+ }} R O S A 26^{\text {PYFP }}$ mice stained for GFP. Cryosections were from unirradiated or lethally irradiated (12 Gy) mice receiving no T cells, syngeneic B6 CD4+ $T$ cells, or allogeneic BALB/c CD4+ $T$ cells. (C and D) Immunofluorescence microscopy images of LN cryosections from T $^{\text {Ccl19-Cret }} R O S A 26^{\text {YYFP }}$ mice stained for B220 and CD3 (C, top panel); eYFP, CD11b, and CD169 (C, bottom panel); eYFP and PDPN (D, top panel); and eYFP and CD35 (D, bottom panel). Cryosections were from unirradiated or lethally irradiated (12 Gy) mice receiving allogeneic BALB/C CD4 ${ }^{+}$T cells on day 1.5 after transplantation. Data are representative of 2 experiments. 
A

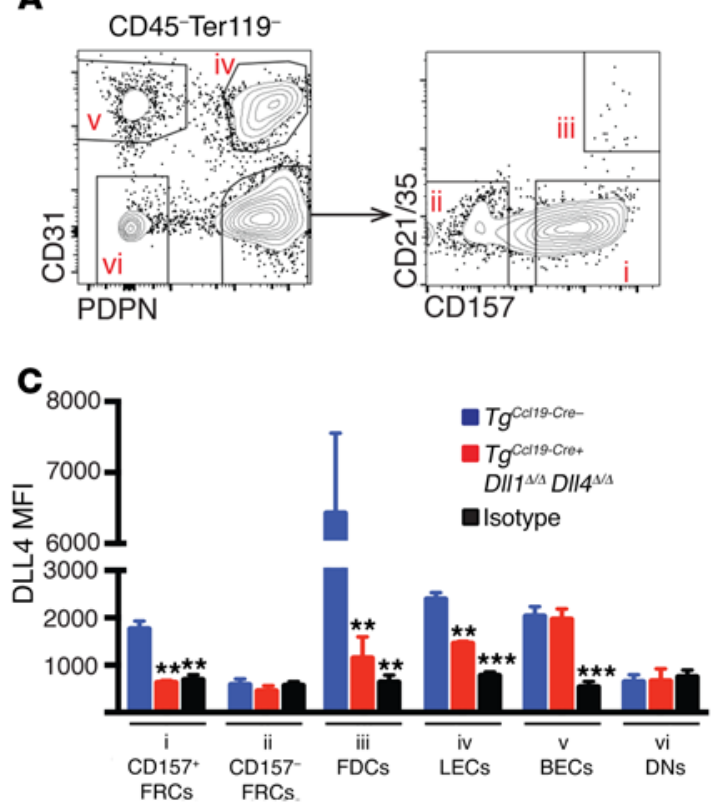

B

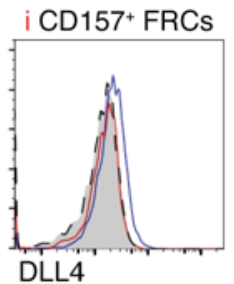

iv LECs

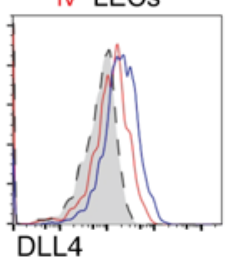

ii CD157- FRCs

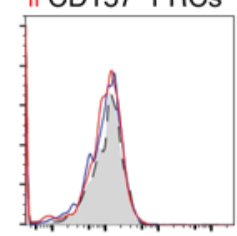

BECs

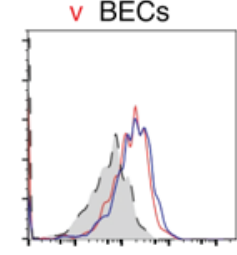

iii CD21+
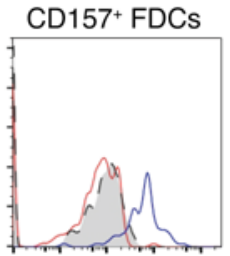

-Isotype

- Tg colta-cre-

$-T g^{\text {cocho-cret }}$

DII1 $1^{N /} D \| 4^{N a}$

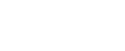

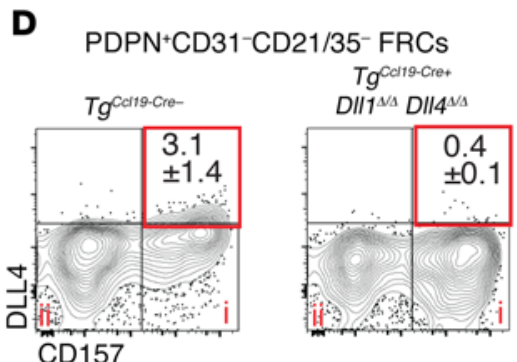
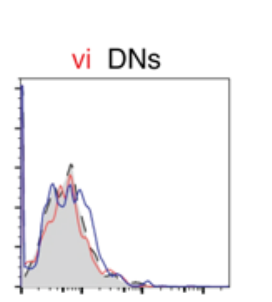

CD157

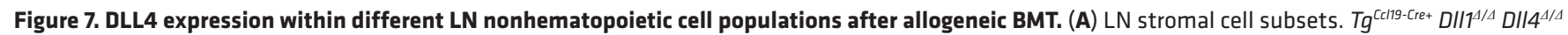
and $\mathrm{Tg}^{\text {ccl19-Cre- }}$ littermate control mice were lethally irradiated before infusion of allogeneic BALB/c splenocytes. LNs were collected on day 1.5 after transplantation and enzymatically digested. Dot plots show representative flow cytometric analysis of CD45-Ter119- nonhematopoietic stromal cells. (B) DLL4 expression in LN-resident nonhematopoietic cell subsets. Roman numerals refer to the cell populations shown in A. (C) MFI comparing DLL4 expression in stromal cell subsets from $\operatorname{Tg}^{\text {Ccl19-Cre- }}$ versus $\mathrm{Tg}^{\text {Ccl19-Cre+ }}$ DII1 ${ }^{1 / 4}$ DII4 ${ }^{4 / 4}$ mice as well as isotype staining in controls. ${ }^{* *} P<0.01$ and ${ }^{* * *} P<0.001$, by unpaired 2-tailed Student's $t$ test with Sidak's correction for multiple comparisons. (D) Representative flow cytometric plots of PDPN ${ }^{+}$CD31-CD21/35- FRCs showing DLL4 expression in the CD157 ${ }^{\text {hi }}$ subset. Data are representative of at least 3 experiments.

Genetic inactivation of DLL1/4 ligands within Ccl19-Cre ${ }^{+}$stromal cells preserves immune homeostasis and classical functions of FRCs. Among fibroblastic stromal cells, FRCs provide survival and migration cues to naive T cells (42), form conduits for antigen trafficking (43), and support the overall SLO infrastructure (37, 44-48). Physical loss of FRCs disrupts immune homeostasis, leading to profoundly impaired immune responses (37). To determine whether these FRC functions were preserved in $\mathrm{Tg}^{\text {Ccll9-Cret }}$ $D l l 1^{\Delta / \Delta} D l l 4^{\Delta / \Delta}$ mice, we studied these mice during steady state and in the peri-transplantation period. SLOs from nonirradiated $\mathrm{Tg}^{\text {Ccl19-Cre+ }} \mathrm{D} l l 1^{1 / \Delta} \mathrm{D} l l 4^{\Delta / \Delta}$ mice had normal lymphocyte numbers, naive/memory T cell distribution, and $I l 7$ expression in FRCs (Figure 4, A-D). After allo-BMT, normal numbers of donor T cells were recovered upon Dll1/4 inactivation in FRCs and showed no impact on $\mathrm{T}$ cell homing or survival (Figure $5 \mathrm{~A}$ ). Donor $\mathrm{T}$ cell proliferation was maintained in $\mathrm{Tg}^{\text {Cll19-Cre+ }} \mathrm{Dll1}^{1 / \Delta} \mathrm{Dll} 4^{4 / \Delta}$ recipients (Figure $5, \mathrm{~B}$ and $\mathrm{C}$ ), or was only mildly decreased at early time points for $\mathrm{CD}^{+} \mathrm{T}$ cells (Figure 5B). Donor $\mathrm{CD} 4^{+}$and $\mathrm{CD}^{+} \mathrm{T}$ cells normally upregulated the early activation markers CD44 (Figure 5, D and E) and CD69 (not shown). CD25 was decreased in $\mathrm{Tg}^{\text {Ccl19-Cre+ }}$ Dll1 $1^{\Delta / \Delta}$ Dll4 $4^{\Delta / \Delta}$ hosts (Figure 5, D and E), consistent with reports that Notch can regulate IL-2 receptor subunit $\alpha$ (Il2ra) expression in T cells (49-51). We also observed a decreased abundance of the Notch target gene transcripts deltex 1, E3 ubiquitin ligase (Dtx1), tribbles pseudokinase 2 (Trib2), and hairy and enhancer of split 1 (Hes1) in donor CD4 $4^{+} \mathrm{T}$ cells (Figure $5 \mathrm{~F}$ ). However, phosphatase and tensin homolog (Pten) mRNA was unchanged, indicating that Hes1-mediated Pten repression did not operate in alloreactive $\mathrm{T}$ cells $(52,53)$. Other genes, including $M y c$, that were previously identified as Notch transcriptional targets in T cell acute lymphoblastic leukemia were expressed at normal levels (Figure $5 \mathrm{~F}$ and refs. 54, 55). Altogether, DLL1/4 loss in FRCs maintained T cell recruitment and initial activation, which is consistent with our observation of preserved classical FRC functions but selective loss of DLL1/4-mediated instructive signals to incoming T cells.

Irradiation rapidly alters the microanatomy of SLOs. To assess the impact of allo-BMT on SLO organization with respect to Ccl19$\mathrm{Cre}^{+}$fibroblastic stromal cells, we studied $\mathrm{Tg}^{\text {Ccll9-Cre+ }} \mathrm{ROSA}^{\text {C }} 6^{\text {eYFP }}$ mice. We found that allo-BMT reduced LN cellularity due to loss of radiosensitive hematopoietic cells, while absolute numbers of $\mathrm{eYFP}^{+}$cells were preserved (Figure 6A). Flow cytometric analysis and immunofluorescence microscopy revealed markedly increased relative frequencies of $\mathrm{eYFP}^{+}$stromal cells in $\mathrm{LN}$ and spleen after allo-BMT (Figure 6, A and B, and Supplemental Figure 7A), concomitant with depletion of radiosensitive lymphocytes and thickening of the subcapsular macrophage layer (Figure 6C and Supplemental Figure 7B). $\mathrm{eYFP}^{+}$fibroblastic cells from allo$\mathrm{BMT}$ mice were located within both the $\mathrm{T}$ zone and $\mathrm{B}$ follicles, as 
A
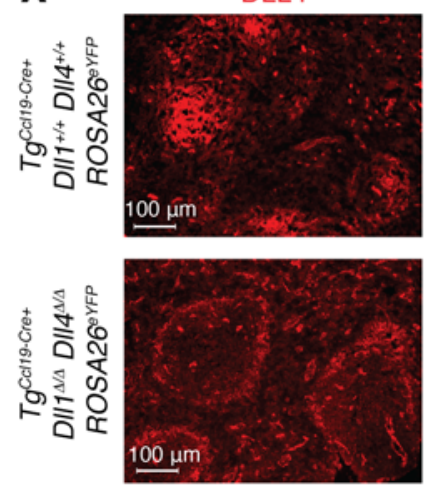

B
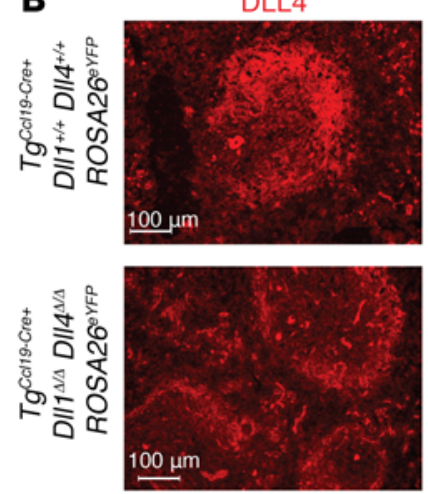

C

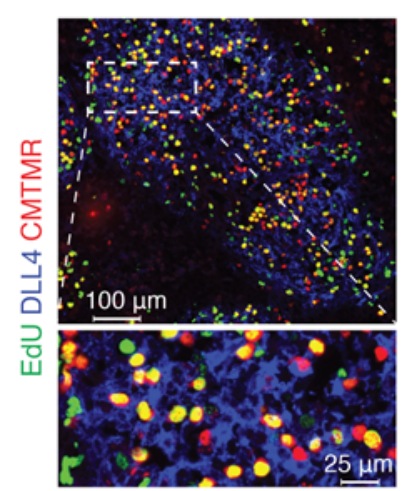

DLL4 CCL19-eYFP
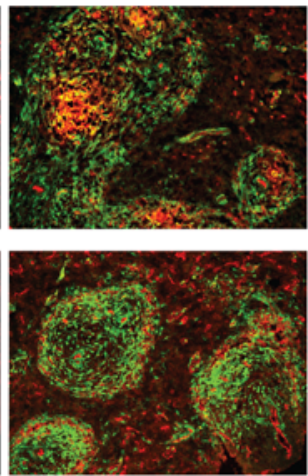

DLL4 CCL19-eYFP
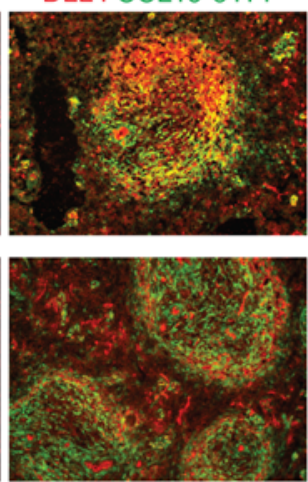

D

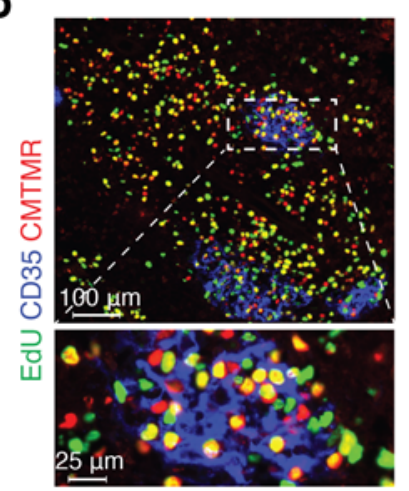

CD35

CD157
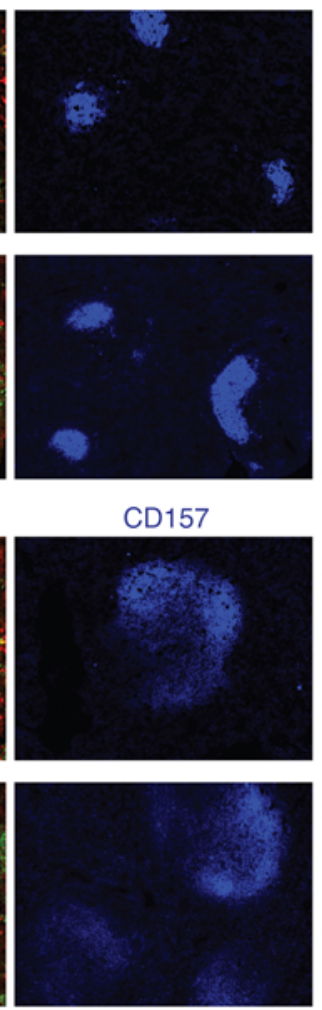

E

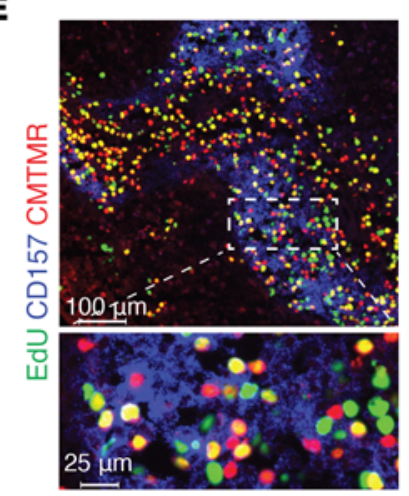

Figure 8. Fibroblastic niches in spleen express DLL1/4 Notch ligands and localize next to alloreactive T cells. (A and B) Immunofluorescence microscopy

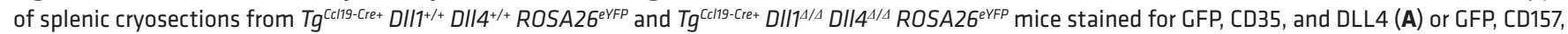
and DLL4 (B). (C-E) Immunofluorescence microscopy of splenic cryosections from lethally irradiated (8.5 Gy) BALB/c mice transplanted with CMTMRlabeled alloantigen-specific CD4+ 4C TCR-transgenic cells and pulsed with EdU 12 hours prior to organ collection to label proliferating cells. Cryosections were incubated with Alexa Fluor 488 picolyl azide to reveal EdU, along with anti-DLL4 (C), anti-CD35 (D), or anti-CD157 (E). Organs were collected on day 1.5 after transplantation. Data are representative of at least 2 experiments.

delineated by the stromal markers podoplanin (PDPN) and CD35, respectively. T zone $\mathrm{Ccl19}-\mathrm{Cre} \mathrm{C}^{+}$fibroblastic cells showed increased staining intensity for PDPN, while CD35, CD157/BP3, and mucosal vascular addressin cell adhesion molecule 1 (MAdCAM-1) staining of stromal cells in B follicles was also highly apparent (Figure 6D and Supplemental Figure 7C). The increased staining intensity could be related at least in part to the rise in stromal cell density within a given surface area after irradiation (Figure 6B). Thus, allo-BMT rapidly altered the spatial organization of lymphoid organ-resident cells, exposing donor T cells to a dense network of stromal cells.
Defined fibroblastic niches deliver Notch ligands to donor alloreactive $T$ cells. We next investigated the distribution of Notch ligands in SLOs after allo-BMT, focusing on DLL4, since it is the dominant Notch ligand driving GVHD (14). We examined cell-surface DLL4 within 6 distinct populations of Ter119- $\mathrm{CD}^{-} 5^{-} \mathrm{LN}$ stromal cells, as defined by expression of CD31, PDPN, CD157/BP3, and CD21/35 (Figure 7). Comparison of control $\mathrm{Tg}^{\text {Ccll9-Cre- }}$ and $\mathrm{Tg}^{\text {Ccll9-Cret }} \mathrm{Dll1}^{1 / 4}$ Dll4 $4^{4 / 4}$ mice identified cellular subsets expressing functionally relevant Notch ligands after allo-BMT. Interestingly, DLL4 expression was not uniformly distributed among all $\mathrm{Ccl19}-\mathrm{Cre}^{+}$stromal cells, but was observed in a fraction of PDPN ${ }^{+} \mathrm{CD} 31^{-}$FRCs marked by 
high levels of CD157/BP3, and in $\mathrm{PDPN}^{+} \mathrm{CD} 31^{-} \mathrm{CD} 21 / 35^{\text {hi }}$ cells that were immunophenotypically consistent with FDCs. In keeping with the capacity of Ccl19-Cre to lineage trace the majority of CD157 hi FRCs and FDCs (Figure 3A), DLL4 expression was reduced to isotype control levels in these cell populations. LECs expressed slightly decreased levels of DLL4 in $\mathrm{Tg}^{\mathrm{Ccl19-Cre+}} \mathrm{Dll1} 1^{1 / 4} \mathrm{Dll} 4^{4 / 4}$ mice, consistent with the Ccl19-Cre activity we observed in a small fraction of LECs (Figure 3A). We found that PDPN ${ }^{+} \mathrm{CD} 31^{-} \mathrm{CD} 157^{\text {lo }} \mathrm{FRCs}$ had no detectable DLL4, while BECs expressed DLL4 in both control and $\mathrm{Tg}^{\mathrm{Ccll9-Cre+}} \mathrm{Dll1}^{4 / \Delta} \mathrm{Dll} 4^{4 / 4}$ mice (Figure 7).

In the spleen, characterization of stromal cells by flow cytometry is more challenging than in LNs due to difficulties in isolation and the presence of many red pulp fibroblasts (39). Tg ccl19-Cre expression induced ROSA26-eYFP expression in a high proportion of $\mathrm{PDPN}^{+} \mathrm{CD} 31^{-} \mathrm{CD} 157^{\mathrm{hi}}$ and $\mathrm{PDPN}{ }^{+} \mathrm{CD} 31^{-} \mathrm{CD} 21 / 35^{\mathrm{hi}}$ stromal cells that were phenotypically similar to their LN counterparts (Supplemental Figure 8, A and B). Histological evaluation revealed that these cells were restricted to the white pulp cords and most likely represented T zone FRCs and B zone FDCs (Supplemental Figure $\left.7, \mathrm{~A}^{-} \mathrm{C}\right)$. Both cell populations expressed surface DLL4 that was abrogated by Ccl19-Cre-mediated Dll4 inactivation (Supplemental Figure 8C). eYFP was also detected in fewer than $10 \%$ of the rare $\mathrm{PDPN}^{+} \mathrm{CD} 31^{-} \mathrm{CD} 157^{\text {lo }}$ cells and in fewer than $2 \%$ of $\mathrm{PDPN}^{-}$ CD $31^{-}$cells (which are heterogeneous and most likely include red pulp-derived fibroblasts). However, flow cytometry did not detect surface DLL4 in these latter cell types, a finding consistent with our observation of restricted expression of DLL4 in fibroblast subsets of the white pulp.

Immunofluorescence microscopy of spleens from $\mathrm{Tg}^{\text {Ccl19-Cre+ }}$

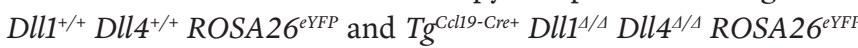
allo-BMT mice provided anatomical landmarks and demonstrated that, within white pulp areas, only a subset of Ccl19-Cre lineage-traced $\mathrm{eYFP}^{+}$cells expressed high levels of DLL4 protein. The coexpression of CD35 and CD157 and the organization in a follicular morphology point to FDC-like cells as being the highest expressors of DLL4. We observed loss of DLL4 expression in FDClike cells, identified as eYFP ${ }^{+} \mathrm{CD}^{2} 5^{+}$(Figure $8 \mathrm{~A}$ ), and in $\mathrm{eYFP}^{+}$ $\mathrm{CD}_{157^{+}}$cells (Figure 8B) from $\mathrm{Tg}^{\text {Cll19-Cre+ }} \mathrm{Dll1}^{4 / \Delta} \mathrm{Dll} 4^{4 / \Delta} \mathrm{ROSA}_{26^{\text {eYFP }}}$ mice. Loss of DLL4 in FRCs could not be assessed histologically due to low signals but was supported by flow cytometric data (Supplemental Figure 8C). To assess whether alloantigen-specific $\mathrm{T}$ cells first localized next to DLL4-expressing stromal cells in SLOs after allo-BMT, we injected $\mathrm{CD}^{+}{ }^{+} \mathrm{C} \mathrm{T}$ cell receptor-transgenic (TCR-transgenic) T cells specific to recipient I- $\mathrm{A}^{\mathrm{d}} \mathrm{MHC}$ class II and tracked these alloantigen-specific T cells during their early window of Notch sensitivity. Using EdU incorporation, we detected proliferating donor $4 \mathrm{C} \mathrm{T}$ cells only within white pulp cords, close to both DLL4-expressing CD $157^{+}$and $\mathrm{CD} 35^{+}$fibroblastic stromal cells (Figure 8, C-E). Altogether, our data suggest that fibroblastic subsets of the white pulp cords form specialized niches that provide DLL4 Notch ligands to incoming $\mathrm{T}$ cells and promote their pathogenic properties at the onset of GVHD.

\section{Discussion}

Preclinical models identified donor and host hematopoietic APCs as critical cellular partners of donor T cells at the onset of GVHD $(2,5-7,56)$. Early interactions between donor T cells and APCs, in concert with inflammatory signals from the microenvironment, are thought to provide essential instructive signals to induce $\mathrm{T}$ cell alloreactivity. Our findings revise this prevailing model of GVHD pathogenesis, as they identify LN- and spleen-resident $\mathrm{Ccl19}-\mathrm{Cre}^{+}$ fate-mapped stromal cells as key initiators of alloimmune $\mathrm{T}$ cell pathogenicity through induction of Notch signals in donor-derived T cells. Contrary to past assumptions, donor and host hematopoietic APCs were not responsible for the delivery of Notch signals to donor T cells, as genetic inactivation of Delta-like Notch ligands within donor and host hematopoietic APCs failed to ameliorate GVHD. In contrast, selective inactivation of Notch ligands within stromal cells derived from Ccl19-Cre-expressing cells resulted in long-term protection from GVHD. Thus, specialized stromal niches are uniquely important in the context of alloimmunity.

In this study, several populations of stromal cells were lineage traced by Ccl19-Cre and should, given our findings, be considered potential essential sources of DLL1/4 Notch ligands available to alloreactive T cells at the onset of GVHD. Our findings identify spleen and LN fibroblastic stromal cells expressing high levels of PDPN and CD157 as prime candidates for sources of DLL1/4 Notch ligands. These DLL4-expressing fibroblasts are referred to as FRCs and are thought to reside predominantly in the T cell zone of SLOs. In addition, we detected high DLL4 expression in stromal cells with characteristics of FDCs. Although these cells are located within follicles that are not typically entered by naive $\mathrm{T}$ cells, post-irradiation changes may change trafficking rules in SLOs and render FDCs accessible to incoming alloreactive $\mathrm{T}$ cells, reminiscent of $\mathrm{T}$ follicular helper cells and memory $\mathrm{CD}^{+} \mathrm{T}$ cells (57). The small fraction of LECs lineage traced by Ccl19-Cre also represents a potential source of Notch ligands in LNs. However, we observed prominent DLL1/4-dependent effects on alloreactive T cells located in the spleen, even during the early peri-transplantation period, when $\mathrm{T}$ cell recirculation is unlikely. As the spleen contains hardly any LECs, these cells are unlikely to be the dominant source of DLL1/4 ligands in GVHD. We observed no DLL4 expression in red pulp cells, where very little Ccl19-Cre activity was detected. Aside from its activity in the spleen and LNs, Ccl19-Cre is also active in fibroblastic cell subsets from Peyer's patches (58). Thus, Peyer's patches and other gut-associated lymphoid structures could also be sites of DLL1/4-mediated Notch activation in T cells during GVHD.

Immunofluorescence microscopy and flow cytometric analysis of SLOs after allo-BMT demonstrated that Delta-like Notch ligand expression was not uniformly distributed throughout all fibroblastic stromal cells of the lymphoid compartment. Instead, we observed focal niches of Notch ligand expression within Ccl19-Cre ${ }^{+}$cells marked by the stromal surface markers CD157 and CD21/35. Concomitant expression of chemokines and Delta-like Notch ligands in resident nonhematopoietic cells within defined SLO niches bears similarities to the coregulated expression of chemokines and DLL4 ligands in cortical thymic epithelial cells. In the thymus, Foxn1 controls expression of CCL21/25 and DLL4, which is critical to attract lymphoid progenitors and induce $\mathrm{T}$ lineage development (26). We speculate that SLOs rely on a similar organizational module to attract immune cells to defined niches with specialized immunological functions in which they are exposed to Notch ligands and other regulatory signals. This is consistent with the role of fibroblastic stromal cells as a source 
of Notch ligands for marginal-zone B cells, ESAM ${ }^{\text {hi }}$ DCs, and T follicular helper cells (32). During alloimmune responses, direct interaction of $\mathrm{T}$ cells with these defined stromal niches may deliver important molecular cues in a temporally and spatially controlled fashion. An in-depth characterization of the cellular and humoral signals delivered within these defined niches should provide additional critical insight into the molecular pathogenesis of GVHD. Furthermore, upstream signals and transcription factors controlling the expression of Delta-like Notch ligands and chemokines in fibroblastic stromal cells remain to be discovered.

It is interesting to speculate as to why alloreactive $\mathrm{T}$ cells derive all their critical DLL1/4-mediated Notch signals from small subsets of fibroblastic cells, while Notch ligands are expressed by multiple other cell types in SLOs, including endothelial cells and hematopoietic cells. The precise pattern of alloreactive $\mathrm{T}$ cell trafficking in SLOs may be important in explaining this phenomenon. We speculate that CCL19 and other chemokines such as CCL21 and CXCL13 recruit incoming alloreactive $\mathrm{T}$ cells into specialized fibroblastic networks that resemble $\mathrm{B}$ and $\mathrm{T}$ zone niches, where $T$ cells engage in durable interactions with fibroblastic cells that induce high-intensity Notch signals. Adhesion molecules and other concomitant signals may also play a role in $\mathrm{T}$ cell retention in this microenvironment. As only limited information is available to date about how alloantigen-specific T cells traffic in SLOs during their initial priming (59), additional investigations will be needed to address these questions.

Among fibroblastic stromal cells, FRCs support steady-state immune homeostasis through the secretion of IL-7, CCL19, and CCL21 $(42,60,61)$. In vitro, FRCs enhance naive CD4 ${ }^{+}$or $\mathrm{CD}^{+}$ $T$ cell survival and viability in an IL-7/CCL19-dependent manner, while Ccl19 loss in vivo results in decreased total numbers of $\mathrm{CD} 4^{+}$ and $\mathrm{CD} 8^{+} \mathrm{T}$ cells. Importantly, genetic Dll1/4 inactivation of Notch ligands with Ccl19-Cre did not negatively impact the ability of FRCs to maintain naive $\mathrm{T}$ cell homeostasis, as the total number of immune cells within LN and spleen and the distribution of naive/ memory cells at steady state were unaffected. Consistent with this notion, $I l 7$ transcripts were unaltered in sort-purified FRCs from $\mathrm{Tg}^{\text {Ccl19-Cre+ }} \mathrm{Dll1}^{4 / \Delta}$ Dll4 ${ }^{\Delta / \Delta}$ mice, showing that DLL1/4 loss did not globally disrupt FRC function.

FRCs can regulate immunity through multiple mechanisms. FRCs form a scaffold to which DCs can adhere and present antigens to naive $\mathrm{T}$ cells, thus using the FRC network as a "road system" for their migration $(45,47,62)$. This random migration is enhanced by the chemokines CCL19 and CCL21, which are constitutively expressed by FRCs. Physical removal of FRCs after SLO development prevents the efficient activation and proliferation of antigen-specific T cells $(37,63,64)$. In contrast, in our studies, genetic Dll1/4 inactivation with Ccl19-Cre preserved T cell homing, as equivalent numbers of donor $\mathrm{CD}^{+}$and $\mathrm{CD} 8^{+} \mathrm{T}$ cells were isolated in SLOs. Furthermore, donor T cells upregulated the early activation markers CD69 and CD44 upon transfer into $\mathrm{Tg}^{\text {Ccl19-Cret }}$ $D l l 1^{1 / 4} \mathrm{D} l l 4^{4 / 4}$ mice, suggesting their preserved ability to encounter and respond initially to alloantigens. Finally, donor T cells demonstrated no obvious impairment in their ability to proliferate in response to antigen. Thus, our observations differ from the broader dysfunction of SLOs observed upon physical elimination of Ccl19$\mathrm{Cr}^{+} \mathrm{FRCs}(37,63,64)$. Instead, our targeted genetic approach sug- gests that fibroblastic stromal cell subsets regulate specific aspects of immune cell biology through dedicated signaling pathways (e.g., Notch), consistent with the delivery of unique activation codes to immune cell subsets. Moreover, the post-transplantation environment may enhance the delivery of Notch signals to incoming $\mathrm{T}$ cells through activation of fibroblastic stromal cells after irradiation and loss of competing radiation-sensitive host lymphocytes.

The precise molecular mechanisms by which early Notch signals increase the pathogenicity of alloreactive $\mathrm{T}$ cells remain to be investigated further. We previously reported that Notch-deprived alloreactive $\mathrm{T}$ cells acquire a hyporesponsive phenotype with decreased TCR/CD28-mediated Ras/MAPK and NF- $\mathrm{BB}$ activation (65). As these changes were observed upon genetic interference with the Notch transcriptional activation complex (11, $14,65)$, the effects of Notch signaling in alloreactive T cells must ultimately be mediated by canonical transcriptional mechanisms. Our observations now provide insights into the critical early window of time during which alloantigen-specific $\mathrm{T}$ cells are exposed to essential Notch signals. Gene expression analysis revealed that only small numbers of known Notch transcriptional targets, including Dtx1, Hes1, Il2ra, and Trib2, were downregulated in this context. More work is necessary to establish whether the profound effects of Notch signaling in alloreactive T cells are accounted for by novel effects of these known Notch target genes, or by other previously unknown transcriptional targets that are controlled by Notch in mature T cells.

Our in vivo results contrast with those of past work identifying a role for stromal cells as negative regulators of immune responses (66-68), as the dominant role of these cells after allo-BMT was to promote rather than restrain alloimmune reactivity. In previous studies, the addition of ex vivo-isolated FRCs to T cell/DC cocultures suppressed $\mathrm{T}$ cell proliferation in a dose-dependent fashion. Suppression was mediated by IFN- $\gamma$-dependent upregulation of NOS2 and COX1/2-dependent metabolites within FRCs. While Nos 2 inactivation resulted in enhanced $\mathrm{T}$ cell proliferation in vivo, the lack of specificity of the genetic targeting strategy made it difficult to assess whether FRCs were in fact responsible for enforcing this suppressive mechanism. Furthermore, the expression of Notch ligands on FRCs was not examined in these in vivo or in vitro studies. In our in vivo studies, irradiation of allo-BMT recipients upregulated the expression of several surface markers on stromal cells, changed their morphology, and resulted in profound remodeling of SLO microanatomy within the first few days of transplantation. Thus, it is possible that the highly inflammatory environment that ensues after irradiation, in combination with the differences in the nature and availability of antigen, could account for the extreme proinflammatory functions of fibroblastic stromal cells after allo-BMT. It is also possible that alloreactive T cells gain unique access to fibroblastic niches from which T cells are typically excluded, such as FDCs or follicular FRCs residing in the outer B cell zone. Alternatively, our observations may reveal a previously unrecognized proinflammatory function of stromal cells mediated by Notch signaling that also operates in other contexts.

With regard to a temporal requirement for Notch signaling, systemic delivery of DLL1/4-blocking antibodies at the time of transplantation had profound effects on $\mathrm{T}$ cell cytokine production, Treg expansion, and overall $\mathrm{T}$ cell alloreactivity, but inhi- 
bition delayed by only 2 days failed to efficiently block GVHD. This narrow window of therapeutic sensitivity is significant in terms of translational applications. Indeed, short-term DLL1/4 inhibition during this critical time has emerged as an attractive therapeutic strategy for preventing GVHD without exposing recipients to the risks of long-term DLL1/4 blockade (69-71). Mechanistically, this narrow window might reflect the temporal delivery of a physical pulse of Notch signaling in defined microanatomical niches after allo-BMT. This physical pulse may result from transient exposure to cellular sources of Notch ligands that are typically inaccessible to $\mathrm{T}$ cells, or from prolonged initial contacts with fibroblastic stromal cell subsets that upregulate DLL1/4. Alternatively, our findings could reflect the existence of a unique window of $\mathrm{T}$ cell sensitivity to Notch signaling during early stages of priming and activation.

Altogether, our study reveals for the first time to our knowledge the existence of specialized subsets of host nonhematopoietic fibroblastic cells that deliver Notch signals to donor $\mathrm{T}$ cells at early stages after allo-BMT to program the pathogenicity of these $\mathrm{T}$ cells. Donor and host hematopoietic APCs were dispensable sources of Notch ligands, thus challenging the widely accepted hypothesis that motile APCs simultaneously provide both antigen and Notch ligands to prime $\mathrm{T}$ cells. These findings illustrate the importance of exploring Notch signaling in vivo using loss-offunction approaches, as relevant sources of Notch ligands may be missing from established in vitro experimental systems. Our work also highlights the utility of precisely targeting immunomodulatory pathways in stromal cells, as we uncovered what we believe to be a previously unrecognized pathogenic role for fibroblastic stromal cells independent of their functions in structural integrity and immune homeostasis. In GVHD, allograft rejection, and other immune disorders, we believe our findings pave the way toward selective inhibition of niche-derived signals that drive deleterious immune responses, without interfering with other essential immunological functions of the lymphoid environment.

\section{Methods}

Mice. BALB/c (H-2 $\left.{ }^{\mathrm{d}}\right), \mathrm{C} 57 \mathrm{BL} / 6$ (H-2 $\left.{ }^{\mathrm{b}}, \mathrm{CD} 45.2\right)$ (B6), and B6-CD45.1 $\left(\mathrm{H}-2^{\mathrm{b}}, \mathrm{CD} 45.1\right)$ mice were bred at the University of Michigan. $T g^{\mathrm{M} x \mathrm{l}-\mathrm{Cre}}$,

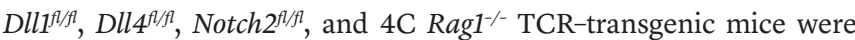
previously described $(24,72-75) . \mathrm{Tg}^{M \times 1-C r e}$ allows for IFN-inducible activation of Cre expression, e.g., via systemic administration of poly(I:C). 4C Rag1/-- mice have a monoclonal population of $\mathrm{CD} 4^{+} \mathrm{T}$ cells specific for I-A $\mathrm{A}^{\mathrm{d}} \mathrm{MHC}$ class II alloantigens, which enables tracking of alloantigen-specific T cells in vivo (72). $\mathrm{Tg}^{M x l^{-C r e}} \mathrm{D} l l 1^{f / f l} \mathrm{D} l l 4^{f / f l}$ mice were maintained on the B6 background and were backcrossed onto the BALB/C background for more than 5 generations. Ccl19-Cre BAC-transgenic mice $\left(\mathrm{Tg}^{\mathrm{Ccl19-Cre}}\right)$ express Cre recombinase in subsets of nonhematopoietic stromal cells under the control of a $90-\mathrm{kb}$ regulatory sequence upstream of the Ccl19 transcriptional start site (32, 36-38). $\mathrm{Tg}^{\text {Ccll9-Cre }}$ mice were crossed with B6 Dll4 $4^{f / f l}$ Dll $1^{f / f l}$ ROSA2 $6^{\text {eYFP }}$ mice (expressing Cre-inducible eYFP under control of the ROSA26 promoter).

Induction and assessment of GVHD. Six- to ten-week-old BALB/c mice or eight- to twelve-week-old B6 recipients underwent allo-BMT as previously described $(11,14,15)$. Both female and male mice were used as recipients and were distributed equally among experimental groups. BALB/c mice received $8.5-9$ Gy irradiation $\left({ }^{137} \mathrm{Cs}\right.$ source) 4 hours prior to allo-BMT, while B6 mice received 2 doses of 6 Gy irradiation $\left({ }^{137} \mathrm{Cs}\right)$ separated by 3 hours. T cell-depleted BM (TCD BM) was prepared with anti-Thy1.2 antibodies and complement (Cedar Lane Laboratories) (14), resulting in over $95 \%$ depletion of Thy $1.2^{+}$cells. $\mathrm{BALB} / \mathrm{c}$ recipients received $5 \times 10^{6}$ to $10 \times 10^{6} \mathrm{TCD} \mathrm{BM} \pm 5 \times 10^{6}$ donor splenocytes, while $\mathrm{B} 6$ recipients received $10 \times 10^{6}$ to $15 \times 10^{6} \mathrm{TCD} \mathrm{BM}$ $\pm 20 \times 10^{6}$ splenocytes. Clinical GVHD score and weight changes were monitored at least weekly, as described previously $(11,14,15,76)$.

Antibody-mediated inhibition of Delta-like Notch ligands. Humanized IgG1-neutralizing antibodies against DLL1, DLL4, and isotype control were described previously $(14,70,77)$. All antibodies were injected i.p. (5 mg/kg twice weekly). The potency and specificity of each antibody batch was verified by assessing their capacity to achieve in vivo depletion of DLL1-dependent marginal-zone B cells or DLL4-dependent thymocytes $(14,24,73)$.

Generation of BM hematopoietic chimeras and GVHD induction. B6-CD45.2 $\mathrm{Tg}^{\mathrm{Mxl}-\mathrm{Cre+}} \mathrm{Dll} \mathrm{f}^{\mathrm{llfl}} \mathrm{Dll} 4^{f / f l}$ donor mice or control littermates received 5 i.p. injections of $50 \mu \mathrm{g}$ poly(I:C) (Amersham) every other day. Two weeks after the last poly(I:C) dose, six- to ten-week-old female B6-CD45.1 mice received 9 Gy of irradiation and were reconstituted with syngeneic BM from poly(I:C)-induced $\mathrm{Tg}^{M x l^{-C r e+}} \mathrm{Dll}^{1 / 4}$ Dll $4^{4 / 4}$ mice or their control littermates. Donor chimerism was quantified 12 weeks later by determining the relative frequency of CD $45.2^{+}$ cells within mature cell populations in blood and spleen. The efficiency of Cre-mediated Dll1 and Dll4 recombination was assessed by PCR in sort-purified blood myeloid cells using the following primers: Dll1 forward: CACACCTCCTACTTACCTGA; Dll1 reverse: GAGAGTACTGGATGGAGCAAG; Dll1 loxas: GGCGCTCAAAGGATATGGGA; Dll4 forward: GTGCTGGGACTGTAGCCACT; Dll4 reverse: TGTTAGGGATGTCGCTCTCC; and Dll4 revdel: CTCGTCTGTTCGCCAAATCTTAC. In other experiments, Notch $2^{f / f l}$ mice were used to generate BM chimeras with poly(I:C)-induced $T g^{M x 1-C r e+} N o t c h 2^{4 / 4}$ or control $T g^{M x l-C r e-}$ Notch $2^{f l / f l}$ donor BM (75).

$\mathrm{BM}$ chimeras were rested at least 12 weeks to allow for establishment of steady-state hematopoiesis before GVHD induction. BM chimeras were irradiated with 2 doses of 5.5 Gy each $\left({ }^{137} \mathrm{Cs}\right)$, separated by 3 hours, and received $8 \times 10^{6} \mathrm{TCD} \mathrm{BM} \pm 30 \times 10^{6}$ splenocytes from $\mathrm{BALB} / \mathrm{c}$ donors (or syngeneic $\mathrm{B} 6$ donors as a negative control). Clinical GVHD score and weight changes were monitored at least weekly (11, 14, 15). For Notch $2^{4 / 4}$ or Notch $2^{+/+}$BM chimeras, transplantation was performed with $10^{7} \mathrm{BALB} / \mathrm{c} \mathrm{BM}$ and $5 \times 10^{6} \mathrm{~T}$ cells (Thy1 selection; EasySep; STEMCELL Technologies).

$L N$ and splenic stromal cell isolation. Stromal cells were isolated from LNs using a modified version of a previously described protocol $(32,42)$. Briefly, peripheral LNs (cervical, axial, brachial, inguinal) from unirradiated or irradiated mice were coarsely chopped with a scalpel and incubated at $37^{\circ} \mathrm{C}$ for 15 minutes in digestion solution containing DMEM, 2\% FBS, $1.2 \mathrm{mM} \mathrm{CaCl}_{2}$, penicillin/streptomycin, and $1.0 \mathrm{mg} / \mathrm{ml}$ collagenase IV (Invitrogen, Thermo Fisher Scientific) and $40 \mu \mathrm{g} / \mathrm{ml}$ DNAse I (Roche). Samples were pipetted gently and reincubated at $37^{\circ} \mathrm{C}$ until all solid material appeared to be dissolved. Suspensions were filtered through a $70-\mu \mathrm{M}$ strainer and analyzed by flow cytometry. For spleen, chopped fragments were incubated at $37^{\circ} \mathrm{C}$ for 15 minutes with $1.0 \mathrm{mg} / \mathrm{ml}$ collagenase IV, $0.5 \mathrm{mg} / \mathrm{ml}$ collagenase D, $0.25 \mathrm{mg} / \mathrm{ml}$ dispase (Invitrogen, Thermo Fisher Scientific), and $40 \mu \mathrm{g} / \mathrm{ml}$ DNAse I (Roche). Samples were pipetted and macroscopic components allowed to settle while 
supernatant was filtered, washed, and resuspended in PBS and $2 \%$ FBS. The remaining solid components were subjected to sequential rounds of digestion, pipetting, and collection of supernatant until no macroscopic components remained.

Flow cytometric analysis. The following antibodies were from BioLegend: CD4 (clone GK1.5); CD8 $\alpha$ (clone 53-6.7); CD19 (clone 6D5); CD11c (clone N418); CD11b (clone M1/70); F4/80 (clone BM8); PDCA1 (clone 129C1); B220 (clone RA3-6B2); MHC II (clone M5/114.15.2); CD44 (clone IM7); CD62L (clone MEL-14); PDPN/gp38 (clone 8.1.1); CD31 (clone 390); Ter119 (clone TER-119); CD157 (clone BP-3); CD25 (clone PC61); CD21/35 (clone 7E9); CD45 (clone 30-F11); TCR $\beta$ (clone H57-597); H-2K ${ }^{\mathrm{b}}$ (clone AF6-88.5); H-2K ${ }^{\mathrm{d}}$ (clone SF1-1.1); IFN- $\gamma$ (clone XMG1.2); TNF- $\alpha$ (clone MP6-XT22); and IL-2 (clone JES6-5H4). Anti-FoxP3 (clone FJK-16s) and anti-CD207/anti-langerin (clone eBioL31) antibodies were from eBioscience. For flow cytometric analysis of DLL4 surface expression, samples were blocked in rat/ mouse serum on ice for 15 minutes, stained on ice with biotinylated anti-DLL4 (clone 9A1.5; a gift of H.R. McDonald, Ludwig Institute for Cancer Research, Lausanne, Switzerland) (78) for 1 hour in $\mathrm{NaN}_{3}$ and EDTA-free FACS buffer, stained with surface markers for 30 minutes on ice, washed twice, and stained in streptavidin-allophycocyanin (streptavidin-APC) (1:100) for 30 minutes on ice. For assessment of $\mathrm{T}$ cell cytokine production, donor splenocytes were stimulated with plate-bound anti-CD3 (2.5 $\mu \mathrm{g} / \mathrm{ml}$; clone 145-2C11; BD Biosciences) and anti-CD28 (2.5 $\mu \mathrm{g} / \mathrm{ml}$; clone 37.51 ; BD Biosciences) for 2 to 3 hours prior to the addition of monensin (GolgiStop; BD Biosciences). Samples were fixed and stained for intracellular proteins according to the manufacturer's instructions. Flow cytometric analysis was performed on a 3-laser Fortessa or 4-laser FACSAria II/III (both from BD). Dead cells were excluded with DAPI (Sigma-Aldrich) or Zombie Aqua Fixable Viability Dye (BioLegend).

Immunofluorescence microscopy. LNs and spleens were fixed in $1 \%$ PFA for 2 hours, sunk in 30\% sucrose overnight, and embedded and frozen in Tissue-Tek O.C.T. (Sakura Finetek) in an ethanol-dry ice bath. Staining of 6- to 8- $\mu$ m-thin cryosections was performed for 60 minutes or overnight at room temperature using the following antibodies: monoclonal anti-CD3e (145-2C11); B220 (RA3-6B2); CD35 (8C12); PDPN/gp38 (8.1.1); MAdCAM-1 (Meca-89); (all purified in house at the Institute of Biochemistry, University of Lausanne, Lausanne, Switzerland); and polyclonal goat anti-DLL4 (AF1389; R\&D Systems). The following secondary antibodies were used: donkey anti-rat biotin; donkey anti-rat Cy3; donkey anti-rabbit Cy3; donkey anti-sheep APC (all from Jackson ImmunoResearch); and streptavidin Alexa Fluor 488 and donkey anti-rabbit Alexa Fluor 647 (both from Invitrogen, Thermo Fisher Scientific). For DLL4 labeling, primary antibodies were detected using a biotinylated donkey anti-goat IgG followed by HRP-coupled streptavidin (Jackson ImmunoResearch) and tyramide signal amplification (Invitrogen, Thermo Fisher Scientific) according to the manufacturer's instructions, but using a borate buffer (0.1 M in PBS, pH 8.5) for tyramide dilution. eYFP was detected using a rabbit anti-GFP antibody followed by Alexa Fluor 488-conjugated donkey anti-rabbit IgG (both from Invitrogen, Thermo Fisher Scientific). Images were acquired on an AxioImager.Z1 microscope with an AxioCam and were processed in Adobe Photoshop. Specifically, image contrast was adjusted using the "levels" tool, while image sharpness was improved with the "unsharpen mask" command. Tissue sections were stained with 3 different fluorochromes, but processed images were often simplified into 2 color images with the Image (NIH) "split channels" and "merge channels" functions.

EdU incorporation and detection. Mice were injected i.p. with 2.5 $\mathrm{mg} / \mathrm{ml}$ 5-ethynyl-2'-deoxyuridine (EdU) 12 hours prior to tissue collection. LNs and spleens were fixed in 1\% PFA for 2 hours, sunk in $30 \%$ sucrose overnight, and embedded and frozen in Tissue-Tek (Sakura Finetek) in an ethanol-dry ice bath. EdU was detected with a Click-iT EdU Alexa Fluor 488 Imaging Kit (Molecular Probes, Thermo Fisher Scientific) according to the manufacturer's instructions.

Quantitative real-time PCR. Donor T cells or host stromal cells were sort purified directly into TRIzol Reagent (Invitrogen, Thermo Fisher Scientific). Total RNA was extracted with phenol/chloroform and purified with an RNeasy Micro Kit (QIAGEN). cDNA was generated with SuperScript II (Invitrogen, Thermo Fisher Scientific) and subjected to quantitative PCR with either TaqMan or SYBR Green PCR Master Mixes on an Eppendorf Mastercycler ep realplex (Applied Biosystems, Thermo Fisher Scientific). Gene expression analysis was performed using the following primers: Dtx1 (Mm00492297_m1, Applied Biosystems); Hes1 (Mm01342805_m1); Il2ra (Mm01340213_ m1); Pten (Mm00477209_m1); Trib2 (Mm00454876_m1); Il7 forward: GTGCCACATTAAAGACAAAGAAG; Il7 reverse: GTTCATTATTCGGGCAATTACTATC; $M y c$ forward: CAGCGACTCTGAAGAAGAGCAAG; Myc reverse: GGGTTTGCCTCTTCTCCACAG; Hprt forward: CTCCTCAGACCGCTTTTTGC; and Hprt reverse: TAACCTGGTTCATCATCGCTAATC. Relative gene expression was determined using the $\Delta \Delta \mathrm{Ct}$ method, with normalization to Hprt.

Statistics. The sample size for in vivo mouse experiments was determined empirically on the basis of prior experience and used to calculate power with the "pwr" statistical package in R. Unless otherwise noted, all statistical tests were done using Prism software (GraphPad Prism7). Briefly, the means of 2 different groups were compared with an unpaired, 2-tailed Student's $t$ test. If the variances of 2 groups differed significantly by $\mathrm{F}$ test, a Welch's correction for $t$ tests was used. If multiple $t$ tests were evaluated at once within a data set, the Holm-Sidak method was used to adjust for multiple comparisons, assuming $\alpha=0.05$. Survival curves were compared using a log-rank (Mantel-Cox) test. Bar graphs were generated with GraphPad Prism.

Study approval. All experiments were performed according to NIH guidelines and approved by the Committee on the Use and Care of Animals of the University of Michigan.

\section{Author contributions}

JC designed and performed the majority of the experiments, analyzed data, and wrote the manuscript. CLE and EP designed, performed, and analyzed experiments. VR, AT, FA, SW, JF, AF, DG, and ITT performed and analyzed transplantation experiments. LS performed immunofluorescence microscopy. QC, LO, and BL generated and provided Ccl19-Cre-transgenic mice. MY and CWS provided DLL1/4-blocking antibodies. PR, BRB, AYH, and DKB participated in study design and data analysis. TVB generated and provided 4C-transgenic mice. UK and FR generated a floxed Dll4 allele, provided Dll1 and Dll4 conditional-KO mice, shared key unpublished information, and participated in the study design. SAL analyzed all immunofluorescence microscopy results, participated in study design, and provided technical assistance. IM supervised the research, designed experiments, analyzed data, and wrote the manuscript. All authors reviewed and edited the manuscript. 


\section{Acknowledgments}

This work was supported by the National Institute of Allergy and Infectious Diseases (NIAID) (R01-AI091627, to IM and R01AI34495, to BRB); the Leukemia and Lymphoma Society (CDP 122714, to IM and TRP 6462-15, to IM and BRB); the Michigan Institute for Clinical and Health Research (to IM); and the Swiss National Science Foundation (to BL, FR, and SAL). Individual support included T32GM007315 from the National Institute of General Medical Sciences (NIGMS) (to JC), T32-GM007863 from NIGMS (to JC and EP), and
T32-HL007762 from the National Heart, Lung, and Blood Institute (to CLE); a research training award from the American Society of Hematology (to VR); and a Career Development Award from the American Society for Blood and Marrow Transplantation (to VR). We thank H.R. McDonald for providing anti-DLL4 antibodies.

Address correspondence to: Ivan Maillard, 6382A Life Sciences Institute, 210 Washtenaw Avenue, Ann Arbor, Michigan 481092216, USA. Phone: 734.763.3599; E-mail: imaillar@umich.edu.
1. Ferrara JL, Levine JE, Reddy P, Holler E. Graft-versus-host disease. Lancet. 2009;373(9674):1550-1561.

2. Blazar BR, Murphy WJ, Abedi M. Advances in graft-versus-host disease biology and therapy. Nat Rev Immunol. 2012;12(6):443-458.

3. Shlomchik WD. Graft-versus-host disease. Nat Rev Immunol. 2007;7(5):340-352.

4. McDonald-Hyman C, Turka LA, Blazar BR. Advances and challenges in immunotherapy for solid organ and hematopoietic stem cell transplantation. Sci Transl Med. 2015;7(280):280rv2.

5. Koyama M, et al. Plasmacytoid dendritic cells prime alloreactive $\mathrm{T}$ cells to mediate graftversus-host disease as antigen-presenting cells. Blood. 2009;113(9):2088-2095.

6. Duffner UA, et al. Host dendritic cells alone are sufficient to initiate acute graft-versus-host disease. J Immunol. 2004;172(12):7393-7398.

7. Shlomchik WD, et al. Prevention of graft versus host disease by inactivation of host antigenpresenting cells. Science. 1999;285(5426):412-415.

8. Koyama M, et al. Recipient nonhematopoietic antigen-presenting cells are sufficient to induce lethal acute graft-versus-host disease. Nat Med. 2011;18(1):135-142.

9. Toubai T, et al. Induction of acute GVHD by sex-mismatched $\mathrm{H}-\mathrm{Y}$ antigens in the absence of functional radiosensitive host hematopoietic-derived antigen-presenting cells. Blood. 2012;119(16):3844-3853.

10. Li H, et al. Profound depletion of host conventional dendritic cells, plasmacytoid dendritic cells, and B cells does not prevent graft-versus-host disease induction. JImmunol. 2012;188(8):3804-3811.

11. Zhang $\mathrm{Y}$, et al. Notch signaling is a critical regulator of allogeneic $\mathrm{CD}^{+} \mathrm{T}$-cell responses mediating graft-versus-host disease. Blood. 2011;117(1):299-308.

12. Riella LV, et al. Blockade of Notch ligand $\delta 1$ promotes allograft survival by inhibiting alloreactive Th1 cells and cytotoxic $\mathrm{T}$ cell generation. J Immunol. 2011;187(9):4629-4638.

13. Roderick JE, et al. Therapeutic targeting of NOTCH signaling ameliorates immune-mediated bone marrow failure of aplastic anemia. J Exp Med. 2013;210(7):1311-1329.

14. Tran IT, et al. Blockade of individual Notch ligands and receptors controls graft-versus-host disease. J Clin Invest. 2013;123(4):1590-1604.

15. Sandy AR, et al. T cell-specific notch inhibition blocks graft-versus-host disease by inducing a hyporesponsive program in alloreactive $\mathrm{CD} 4^{+}$and CD8 $^{+}$T cells. J Immunol. 2013;190(11):5818-5828.
16. Charbonnier LM, Wang S, Georgiev P, Sefik E, Chatila TA. Control of peripheral tolerance by regulatory T cell-intrinsic Notch signaling. Nat Immunol. 2015;16(11):1162-1173.

17. Wood S, et al. Transient blockade of delta-like Notch ligands prevents allograft rejection mediated by cellular and humoral mechanisms in a mouse model of heart transplantation. J Immunol. 2015;194(6):2899-2908.

18. Guruharsha KG, Kankel MW, Artavanis-Tsakonas S. The Notch signalling system: recent insights into the complexity of a conserved pathway. Nat Rev Genet. 2012;13(9):654-666.

19. Kopan R, Ilagan MX. The canonical Notch signaling pathway: unfolding the activation mechanism. Cell. 2009;137(2):216-233.

20. Yamaguchi E, et al. Expression of Notch ligands, Jagged1, 2 and Delta1 in antigen presenting cells in mice. Immunol Lett. 2002;81(1):59-64.

21. Amsen D, Blander JM, Lee GR, Tanigaki K, Honjo $\mathrm{T}$, Flavell RA. Instruction of distinct CD4 T helper cell fates by different notch ligands on antigen-presenting cells. Cell. 2004;117(4):515-526.

22. Schaller MA, et al. Notch ligand Delta-like 4 regulates disease pathogenesis during respiratory viral infections by modulating Th2 cytokines. J Exp Med. 2007;204(12):2925-2934.

23. Mochizuki K, et al. Delta-like ligand 4 identifies a previously uncharacterized population of inflammatory dendritic cells that plays important roles in eliciting allogeneic $\mathrm{T}$ cell responses in mice. J Immunol. 2013;190(7):3772-3782.

24. Koch U, et al. Delta-like 4 is the essential, nonredundant ligand for Notch1 during thymic T cell lineage commitment. JExp Med. 2008;205(11):2515-2523.

25. Hozumi K, et al. Delta-like 4 is indispensable in thymic environment specific for T cell development. JExp Med. 2008;205(11):2507-2513.

26. Calderón L, Boehm T. Synergistic, contextdependent, and hierarchical functions of epithelial components in thymic microenvironments. Cell. 2012;149(1):159-172.

27. Tan JB, et al. Lunatic and manic fringe cooperatively enhance marginal zone $\mathrm{B}$ cell precursor competition for delta-like 1 in splenic endothelial niches. Immunity. 2009;30(2):254-263.

28. Shutter JR, et al. Dll4, a novel Notch ligand expressed in arterial endothelium. Genes Dev. 2000;14(11):1313-1318.

29. Hellström M, et al. Dll4 signalling through Notch1 regulates formation of tip cells during angiogenesis. Nature. 2007;445(7129):776-780.

30. Zheng W, et al. Notch restricts lymphatic vessel sprouting induced by vascular endothelial growth factor. Blood. 2011;118(4):1154-1162

31. Niessen K, et al. The Notch1-Dll4 signaling pathway regulates mouse postnatal lymphatic development. Blood. 2011;118(7):1989-1997.

32. Fasnacht $\mathrm{N}$, et al. Specific fibroblastic niches in secondary lymphoid organs orchestrate distinct Notch-regulated immune responses. J Exp Med. 2014;211(11):2265-2279.

33. Laky K, Evans S, Perez-Diez A, Fowlkes BJ. Notch signaling regulates antigen sensitivity of naive $\mathrm{CD}^{+} \mathrm{T}$ cells by tuning co-stimulation. Immunity. 2015;42(1):80-94.

34. Meng L, et al. The Notch ligand DLL4 defines a capability of human dendritic cells in regulating Th1 and Th17 differentiation. J Immunol. 2016;196(3):1070-1080.

35. Maekawa Y, Ishifune C, Tsukumo S, Hozumi K, Yagita H, Yasutomo K. Notch controls the survival of memory $\mathrm{CD} 4^{+} \mathrm{T}$ cells by regulating glucose uptake. Nat Med. 2015;21(1):55-61.

36. Chai Q, et al. Maturation of lymph node fibroblastic reticular cells from myofibroblastic precursors is critical for antiviral immunity. Immunity. 2013;38(5):1013-1024.

37. Cremasco V, et al. B cell homeostasis and follicle confines are governed by fibroblastic reticular cells. Nat Immunol. 2014;15(10):973-981.

38. Rodda LB, Bannard O, Ludewig B, Nagasawa T, Cyster JG. Phenotypic and morphological properties of germinal center dark zone Cxcl12-expressing reticular cells. JImmunol. 2015;195(10):4781-4791.

39. Fasnacht N, et al. Specific fibroblastic niches in secondary lymphoid organs orchestrate distinct Notch-regulated immune responses. J Exp Med. 2014;211(11):2265-2279.

40. Lewis KL, et al. Notch2 receptor signaling controls functional differentiation of dendritic cells in the spleen and intestine. Immunity. 2011;35(5):780-791.

41. Saito T, et al. Notch2 is preferentially expressed in mature B cells and indispensable for marginal zone B lineage development. Immunity. 2003;18(5):675-685.

42. Link A, et al. Fibroblastic reticular cells in lymph nodes regulate the homeostasis of naive T cells. Nat Immunol. 2007;8(11):1255-1265.

43. Sixt M, et al. The conduit system transports soluble antigens from the afferent lymph to resident dendritic cells in the $\mathrm{T}$ cell area of the lymph node. Immunity. 2005;22(1):19-29.

44. Kaldjian EP, Gretz JE, Anderson AO, Shi Y, Shaw S. Spatial and molecular organization of lymph node T cell cortex: a labyrinthine cavity bounded by an epithelium-like monolayer of fibroblastic 
reticular cells anchored to basement membrane-like extracellular matrix. Int Immunol. 2001;13(10):1243-1253.

45. Katakai T, Hara T, Sugai M, Gonda H, Shimizu A. Lymph node fibroblastic reticular cells construct the stromal reticulum via contact with lymphocytes. JExp Med. 2004;200(6):783-795.

46. Clark SL Jr. The reticulum of lymph nodes in mice studied with the electron microscope. Am JAnat. 1962;110:217-257.

47. Bajénoff $\mathrm{M}$, et al. Stromal cell networks regulate lymphocyte entry, migration, and territoriality in lymph nodes. Immunity. 2006;25(6):989-1001.

48. Chyou S, et al. Coordinated regulation of lymph node vascular-stromal growth first by CD11c ${ }^{+}$ cells and then by T and B cells. JImmunol. 2011;187(11):5558-5567.

49. Mathieu M, Duval F, Daudelin JF, Labrecque N. The Notch signaling pathway controls shortlived effector $\mathrm{CD}^{+} \mathrm{T}$ cell differentiation but is dispensable for memory generation. JImmunol. 2015;194(12):5654-5662.

50. Adler SH, et al. Notch signaling augments T cell responsiveness by enhancing CD25 expression. JImmunol. 2003;171(6):2896-2903.

51. Backer RA, et al. A central role for Notch in effector CD8(+) T cell differentiation. Nat Immunol. 2014;15(12):1143-1151.

52. Wong GW, Knowles GC, Mak TW, Ferrando AA, Zúñiga-Pflücker JC. HES1 opposes a PTENdependent check on survival, differentiation, and proliferation of TCR $\beta$-selected mouse thymocytes. Blood. 2012;120(7):1439-1448.

53. Palomero T, et al. Mutational loss of PTEN induces resistance to NOTCH1 inhibition in T-cell leukemia. Nat Med. 2007;13(10):1203-1210.

54. Herranz D, et al. A NOTCH1-driven MYC enhancer promotes $\mathrm{T}$ cell development, transformation and acute lymphoblastic leukemia. Nat Med. 2014;20(10):1130-1137.

55. Yashiro-Ohtani Y, et al. Long-range enhancer activity determines Myc sensitivity to Notch inhibitors in T cell leukemia. Proc Natl Acad Sci US A. 2014;111(46):E4946-E4953.

56. Magenau J, Runaas L, Reddy P. Advances in understanding the pathogenesis of graft-versushost disease. Br J Haematol. 2016;173(2):190-205.

57. Im SJ, et al. Defining CD8(+) T cells that provide the proliferative burst after PD-1 therapy. Nature. 2016;537(7620):417-421.

58. Gil-Cruz C, et al. Fibroblastic reticular cells regulate intestinal inflammation via IL-15mediated control of group 1 ILCs. Nat Immunol. 2016;17(12):1388-1396.

59. Lin KL, et al. Intravital imaging of donor allogeneic effector and regulatory $\mathrm{T}$ cells with host dendritic cells during GVHD. Blood. 2014;123(10):1604-1614.

60. Malhotra D, Fletcher AL, Turley SJ. Stromal and hematopoietic cells in secondary lymphoid organs: partners in immunity. Immunol Rev. 2013;251(1):160-176.

61. Malhotra D, et al. Transcriptional profiling of stroma from inflamed and resting lymph nodes defines immunological hallmarks. Nat Immunol. 2012;13(5):499-510.

62. Katakai T, Hara T, Lee JH, Gonda H, Sugai M, Shimizu A. A novel reticular stromal structure in lymph node cortex: an immuno-platform for interactions among dendritic cells, T cells and B cells. Int Immunol. 2004;16(8):1133-1142.

63. Scandella E, et al. Restoration of lymphoid organ integrity through the interaction of lymphoid tissue-inducer cells with stroma of the T cell zone. Nat Immunol. 2008;9(6):667-675.

64. Novkovic M, et al. Topological small-world organization of the fibroblastic reticular cell network determines lymph node functionality. PLOS Biol. 2016;14(7):e1002515.

65. Sandy AR, et al. T cell-specific notch inhibition blocks graft-versus-host disease by inducing a hyporesponsive program in alloreactive $\mathrm{CD} 4^{+}$and
CD8 ${ }^{+}$T cells. J Immunol. 2013;190(11):5818-5828.

66. Siegert S, et al. Fibroblastic reticular cells from lymph nodes attenuate T cell expansion by producing nitric oxide. PLoS One. 2011;6(11):e27618.

67. Khan O, Headley M, Gerard A, Wei W, Liu L, Krummel MF. Regulation of T cell priming by lymphoid stroma. PLoS One. 2011;6(11):e26138.

68. Lukacs-Kornek V, et al. Regulated release of nitric oxide by nonhematopoietic stroma controls expansion of the activated $\mathrm{T}$ cell pool in lymph nodes. Nat Immunol. 2011;12(11):1096-1104.

69. Yan M, et al. Chronic DLL4 blockade induces vascular neoplasms. Nature. 2010;463(7282):E6-E7.

70. Ridgway J, et al. Inhibition of Dll4 signalling inhibits tumour growth by deregulating angiogenesis. Nature. 2006;444(7122):1083-1087.

71. Yan M. Therapeutic promise and challenges of targeting DLL4/NOTCH1. Vasc Cell. 2011;3:17.

72. Brennan TV, et al. A new T-cell receptor transgenic model of the $\mathrm{CD} 4^{+}$direct pathway: level of priming determines acute versus chronic rejection. Transplantation. 2008;85(2):247-255.

73. Hozumi K, et al. Delta-like 1 is necessary for the generation of marginal zone B cells but not $\mathrm{T}$ cells in vivo. Nat Immunol. 2004;5(6):638-644.

74. Kuhn R, Schwenk F, Aguet M, Rajewsky K. Inducible gene targeting in mice. Science. 1995;269(5229):1427-1429.

75. McCright B, Lozier J, Gridley T. Generation of new Notch2 mutant alleles. Genesis. 2006;44(1):29-33.

76. Cooke KR, et al. An experimental model of idiopathic pneumonia syndrome after bone marrow transplantation: $\mathrm{I}$. The roles of minor $\mathrm{H}$ antigens and endotoxin. Blood. 1996;88(8):3230-3239.

77. Wu Y, et al. Therapeutic antibody targeting of individual Notch receptors. Nature. 2010;464(7291):1052-1057.

78. Fiorini E, et al. Cutting edge: thymic crosstalk regulates delta-like 4 expression on cortical epithelial cells. J Immunol. 2008;181(12):8199-8203. 